\title{
Parte III. Apoyo del laboratorio de microbiología y anatomía patológica en el diagnóstico y manejo de infecciones en el paciente con cáncer y trasplante de precursores hematopoyéticos
}

\author{
Marcela Ferrés ${ }^{1}$, Mónica Lafourcade², Pilar Gambra ${ }^{3}$, Inés Cerón ${ }^{4}$, Ernesto Payá ${ }^{5}$ y David Oddó6
}

\begin{abstract}
Support of the laboratory of microbiology and pathological anatomy in the diagnosis and management of infections in cancer patients and transplantation of hematopoietic stem cell transplant receptors
\end{abstract}

The confrontation of the differential and etiological diagnosis of the infectious diseases of cancer patients, including hematopoietic stem cells transplant (HSCT) recipients, must correspond to an informed, timely decision that directly affects medical behavior that determines a better survival and quality of life for patients. The main goal of this work was to contribute to the management of these patients developing a useful tool for the clinician to make these decisions. For that, infections were grouped by compromised systems, differentiating the possible etiological agents in bacteria, viruses, fungi and parasites, highlighting the relevant diagnostic tests, mentioning the recommended techniques together with the optimal sample type for proper processing. In addition, under each group of techniques we added the item "level of requirement" to suggest what, in the opinion of the authors and the existing evidence, must be mandatory to have at local level or can be derivable to another laboratory.

Keywords: Immunocompromised host; infections; microbiology specimen.

Palabras clave: Inmunocomprometido; infecciones; muestras microbiológicas.

\begin{tabular}{|l|}
\hline Abreviaturas \\
ARNr : Ácido ribonucleico ribosomal \\
BDG $\quad: \beta$-D- glucano \\
CMV : Citomegalovirus \\
EDTA : Ácido etilendiaminotetraacético (anticoagulante) \\
EFI : Enfermedad fúngica invasora \\
EICH $\quad:$ Enfermedad de injerto contra hospedero \\
EORTC: European Organization for Research and Treatment \\
MSG $\quad$ of Cancer/Mycoses Study Group \\
GM : Galactomanano \\
LBA : Lavado broncoalveolar \\
NF $\quad:$ Neutropenia febril \\
TDM : Toma de muestra \\
TPH : Trasplante de precursores hematopoyéticos \\
VEB : Virus de Epstein Barr \\
\hline
\end{tabular}

\section{Introducción}

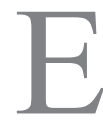
1 estudio etiológico de las enfermedades infecciosas en los pacientes con cáncer, incluyendo los receptores de trasplante de precursores hematopoyéticos $(\mathrm{TPH})$, plantea un importante reto al momento de seleccionar el estudio a realizar. La identificación oportuna del agente causal es de particular importancia en estos pacientes, pues repercute directamente en una conducta médica que determina finalmente una mejor sobrevida y calidad de vida de los pacientes.

La solicitud de los exámenes microbiológicos específicos y estudio anatomopatológico debe considerar el análisis de variados aspectos del paciente tales como su patología de base, la categoría de la inmunosupresión, el momento de evolución de la enfermedad y las terapias recibidas, el entorno epidemiológico entendido como el ambiente que lo rodea y sus contactos, las infecciones propias de la época del año y la zona geográfica, el uso previo de vacunas $\mathrm{y}$, por supuesto, las manifestaciones clínicas del episodio actual junto al acabado examen físico, que permitan la formulación de una hipótesis diagnóstica y de estudio.

Desde el punto de vista del agente y la elección del examen más adecuado para su diagnóstico, el médico tratante debe estar en conocimiento de la patogenia, la importancia de los diferentes sitios anatómicos y tiempos de excreción de los agentes, para así escoger "la o las" muestra(s) biológica(s) más representativa(s) y con ello, tener la mejor aproximación diagnóstica con rapidez, e idealmente, a un costo razonable.

El laboratorio de microbiología puede disponer de las mejores técnicas diagnósticas y de personal altamente
'Departamento de Enfermedades Infecciosas e Inmunología Pediátrica. Escuela de Medicina. Pontificia Universidad Católica de Chile. Santiago, Chile. 2Laboratorio de Microbiología. Clínica Santa María. Santiago, Chile.

${ }^{3}$ Unidad de Infectología adultos. Clínica Santa María. Santiago, Chile.

${ }^{4}$ Departamento de Enfermedades Infecciosas del Adulto. Escuela de Medicina. Pontificia Universidad Católica de Chile. Santiago, Chile. ${ }^{5}$ Hospital Dr. Exequiel González Cortés. Departamento de pediatría Universidad de Chile. Santiago, Chile.

${ }^{6}$ Departamento de Anatomía Patológica. Escuela de Medicina. Pontificia Universidad Católica de Chile. Santiago, Chile.

Los autores declaran ausencia de conflicto de interés. El presente trabajo no recibió financiamiento alguno.

Correspondencia a: Marcela Ferrés Garrido mferres@med.puc.cl 
capacitado para su procesamiento; su desempeño dependerá, sin embargo, en gran medida, de la calidad de las muestras; por ello es prioritario no perder de vista este aspecto. Esto exige capacitación continua del personal que asegure una correcta toma y transporte de muestras microbiológicas ${ }^{1}$.

Es importante también resaltar las limitaciones que impone la condición de inmunosupresión del paciente al momento de evaluar el rendimiento de algunas técnicas diagnósticas como también la interpretación cuidadosa de los resultados, a la luz de la enfermedad de base.

Muchas metodologías diagnósticas, por su costo y por la baja prevalencia del agente que detectan, resulta más conveniente centralizarlas en pocos laboratorios; sin embargo, otras técnicas deben estar disponibles en los centros que atienden pacientes inmunocomprometidos para asegurar un acceso rápido y seguro a un diagnóstico microbiológico específico.

El objetivo de este trabajo es desarrollar una herramienta útil al médico clínico, agrupando las infecciones por sistemas comprometidos y diferenciando los posibles agentes etiológicos en bacterias, virus, hongos y parásitos, explicitando los exámenes diagnósticos más relevantes, mencionando la(s) técnica(s) recomendada(s) junto con el tipo de muestra óptima para su adecuado procesamiento. En consideración de la importancia del estudio histológico de las muestras obtenidas, se incluyó una sección que señala el aporte del estudio anatomopatológico en el diagnóstico de complicaciones infecciosas de este grupo de pacientes. De manera adicional, se incorporó el ítem "nivel de requerimiento" para sugerir lo que, a juicio de los autores y la evidencia existente, debe estar presente obligatoriamente en el centro o puede ser derivable a otro laboratorio.

En este artículo se revisan y entregan recomendaciones en los siguientes aspectos:

- Importancia de la toma de muestra (TDM) en el diagnóstico microbiológico, resaltando los elementos claves para asegurar una muestra de calidad que permita la mejor opción para el diagnóstico. Es responsabilidad de cada centro la elaboración de un manual de toma y transporte de muestras. Este documento sólo constituye una recomendación general.

- Exámenes de laboratorio utilizados para el diagnóstico de las enfermedades infecciosas. Se presentan en la modalidad de tablas que resumen los exámenes imprescindibles y que deberían estar disponibles en la institución que atiende a pacientes con cáncer y/o TPH, o que puedan ser derivados a centros de referencia. Estas tablas se han organizado desde un punto de vista sindromático para facilitar el uso por el equipo tratante.

- Exámenes de cribado de infecciones, previo al inicio de quimioterapia del cáncer o trasplante.
- Exámenes de anatomía patológica con descripción de las distintas técnicas de las que se dispone para estudios de importancia en el diagnóstico de etiología infecciosa en este grupo de pacientes.

\section{Importancia de la toma de muestra}

La elección del tipo de muestra microbiológico es de responsabilidad del médico que solicita el examen. Ésta debe ser representativa del cuadro infeccioso que se desea estudiar y es muy relevante que su recolección y transporte cumpla con los requerimientos exigidos por el laboratorio.

Algunas consideraciones fundamentales para una buena TDM y transporte ${ }^{1}$ :

- Cada centro debe elaborar su propio manual de TDM con aspectos generales y específicos fundamentados en la literatura científica (Ej.: tipos y marcas de insumos para la toma y el transporte de muestras).

- Lo ideal es que la TDM microbiológica se realice antes del inicio de terapia antimicrobiana.

- Las muestras de mala calidad no permiten la ejecución de un examen confiable. Idealmente debe intentarse la repetición de la TDM para la correcta interpretación de los resultados.

- Es recomendable la TDM de sitios estériles y ser cautelosos en la interpretación de resultados de sitios como el tracto respiratorio alto, piel y tejidos blandos, entre otras, considerando el microbioma humano.

- Privilegie la TDM por punción, aspirado o biopsia de tejido y no tomar cultivos de superficie de tejidos por tórula por la escasa cantidad de muestra (aproximadamente $0,05 \mathrm{ml}$ ) e inóculo heterogéneo.

- Recuerde que el paciente objetivo es un hospedero "frágil" y que existen momentos como los períodos de neutropenia profunda, en que deben ser evitados algunos procedimientos invasores ya que pueden favorecer la translocación microbiológica.

- Use medios de transporte cuando las muestras son recolectadas con tórula.

- La muestra de tejido debe enviarse en un recipiente hermético y estéril, con solución salina fisiológica ("suero fisiológico") sin ningún aditivo y a temperatura ambiente. En el caso de exámenes virológicos use medios de transporte especiales (ej.: medio de transporte universal MTU).

- Rotule clara y adecuadamente las muestras especificando el sitio anatómico y la forma de recolección para su correcto procesamiento e interpretación.

- Obtenga la mayor cantidad de muestra posible para que ésta sea representativa del sitio de TDM.

- Transporte al laboratorio lo más rápido posible para no alterar la calidad de la muestra. 
- El transporte de la muestra, para estudio viral debe ser refrigerada y para cultivos bacterianos o micológicos a temperatura ambiente; como excepción, las orinas también deben ser refrigeradas hasta ser cultivadas.

\section{Exámenes de laboratorio utilizados para el diagnóstico de las enfermedades infecciosas}

\section{Infecciones causadas por bacterias}

Las infecciones bacterianas se diagnostican en el laboratorio por métodos directos e indirectos.

- Métodos directos tradicionales: permiten visualizar e identificar el microorganismo mediante observación microscópica, uso de distintos tipos de tinciones y cultivos. El cultivo es la piedra angular del diagnóstico microbiológico, pero no es practicable para todos los agentes.

- Métodos directos por técnicas inmunológicas y moleculares: pueden ser utilizados cuando el agente no permite su tinción ni su cultivo o simplemente su crecimiento es muy laborioso y lento; estas técnicas detectan parte del agente, por ejemplo, antígenos o material genético. Si bien los estudios moleculares han resultado un gran avance en el diagnóstico de ciertos microorganismos, la mayoría de los estudios de susceptibilidad a antimicrobianos se sustenta en el cultivo, por tanto, los cultivos continúan siendo indispensables para la elección de la terapia.

- Métodos indirectos: corresponden al estudio de la respuesta inmune específica del paciente, conocida como serología, que presenta la limitante de baja sensibilidad en pacientes cuya inmunidad está disminuida.

Cada una de estas técnicas presenta ventajas y desventajas que radican en varios factores, entre ellos, el microorganismo que se esté sospechando y el tipo de paciente que se estudiará. Por ello resulta crucial disponer de una diversidad de técnicas para cubrir el enorme abanico de posibilidades etiológicas. Junto con lo anterior, en el diagnóstico bacteriano es muy importante la correcta interpretación de los resultados, más aún si se considera que muchas bacterias de la microbiota normal pudieran interpretarse como agentes causales o, al contrario, pasar inadvertidas en una determinada muestra si no existe un análisis riguroso de la situación particular de cada caso.

Una técnica reciente de identificación múltiple es el Panel de Sepsis (BCID) FilmArray ${ }^{\circledR}$ que analiza 24 patógenos $\mathrm{y}$ tres genes de resistencia antimicrobiana asociados con las infecciones del torrente sanguíneo. Puede identificar patógenos en nueve de cada 10 hemocultivos positivos en una hora. Tiene la capacidad de identificar: Enterococcus spp, Listeria monocytogenes, Staphylococcus sp., Staphylococus aureus, Streptococcus sp, Streptococcus agalactiae, Streptococcus pyogenes, Streptococcus pneumoniae, Acinetobacter baumannii, Haemophilus influenzae, Neisseria meningitidis, Pseudomonas aeruginosa, Enterobacteriaceae, Complejo Enterobacter cloacae, Escherichia coli, Klebsiella oxytoca, Klebsiella pneumoniae, Proteus, Serratia marcescens, Candida albicans, Candida glabrata, Candida krusei, Candida parapsilosis; genes de resistencia: mecA-resistencia a meticilina, van A/B-resistencia a vancomicina, $K P C$ resistencia a carbapenémicos. Otro de los avances recientes en la identificación microbiológica es la espectrometría de masas, específicamente en el MALDI-TOF MS (matrixassisted laser desorption/ionization time-of-flight mass spectrometer) que permite acortar los tiempos y mejorar la exactitud respecto a los métodos de identificación convencional de bacterias y levaduras ${ }^{1-3}$.

\section{Infecciones causadas por hongos}

Los pacientes con cáncer y aquellos sometidos a TPH tienen mayor riesgo de presentar enfermedad fúngica invasora (EFI). Los agentes más frecuentemente involucrados son Candida spp y Aspergillus spp, pero también pueden presentarse infecciones por Cryptococcus spp, Pneumocystis spp, Fusarium spp y Mucorales, entre otros. El diagnóstico temprano de estas infecciones y su oportuno tratamiento impacta en su mortalidad, por lo que una elevada sospecha clínica junto a recursos diagnósticos de laboratorio sensibles y oportunos le otorgarán al paciente una mejor opción de terapia y pronóstico ${ }^{4}$.

Para el diagnóstico de EFI también se cuenta con técnicas directas como tinciones de blanco de calcoflúor para hongos filamentosos y tinta china para Cryptococcus, cultivos de sangre, secreción, colecciones o fluidos estériles, y técnicas indirectas basadas en la detección de antígenos fúngicos circulantes como galactomanano (GM), $\beta$-D-glucano (BDG), antígeno de Cryptococcus spp. El galactomanano es de utilidad en diagnóstico de aspergilosis invasora; sin embargo, también puede resultar positivo en otras infecciones por hongos filamentosos como Fusarium spp. El BDG es un marcador panfúngico porque es componente de la pared de Candida, Aspergillus, Fusarium, Pneumocystis, Trichosporon y Acremonium, pero no forma parte de la pared de los agentes de mucormicosis ni de Cryptococcus $\mathrm{spp}^{5}$.

Una estrategia relevante, destacada durante los últimos años, ha sido el uso de GM, BDG y reacción de polimerasa en cadena (RPC), para la detección temprana de EFI. De hecho, tanto BDG como GM han sido incluidos entre los criterios diagnósticos para EFI de la EORTC/MSG ${ }^{4}$.

El GM se puede realizar en muestras de sangre y lavado broncoalveolar (LBA), existe menos información de su utilidad en líquido cefalorraquídeo (LCR). Su uso es especialmente útil como herramienta de vigilancia en los períodos de alto riesgo en pacientes asintomáticos 
con neutropenia post-quimioterapia o TPH, enfermedad de injerto contra hospedero (EICH) o neutropenia febril (NF). En pacientes adultos, los análisis basados en GM, BDG y RPC son herramientas aceptadas para apoyar el diagnóstico de EFI. Sin embargo, su uso en niños ha sido cuestionada. De acuerdo a estudios publicados de su utilización en niños con cáncer y NF y cribado de EFI como complicación de TPH, los valores de GM y BDG poseen sensibilidades bajas y variables; no obstante, con valores predictores negativos altos, en rangos de 85 a $100 \%$ para cribado y 70 a $100 \%$ en diagnóstico clínico de aspergilosis, pero con resultados menos auspiciosos en el diagnóstico de hongos diferentes a Aspergillus spp $\mathrm{sp}^{6-11}$.

La amplificación del material genético es una aproximación novedosa y prometedora, pero aún en fase de estandarización.

La identificación de especies y el estudio de sensibilidad son relevantes para la elección de agentes antifúngicos, así como en la vigilancia de cambios epidemiológicos que puedan afectar la elección de tratamientos empíricos. Las pruebas de sensibilidad antifúngica deben considerarse ante el aislamiento de Candida no-albicans. Los laboratorios de referencia deben concentrar estos recursos diagnósticos.

Y si bien no es parte del estudio etiológico, resulta de gran importancia en el seguimiento de pacientes en tratamiento con voriconazol, contar con la disponibilidad in situ o en laboratorios de referencia, de medición de concentraciones plasmáticas de voriconazol, considerando su estrecho margen terapéutico, correlación entre concentraciones y desenlace, y las dificultades en poder llegar a concentraciones terapéuticas, especialmente en pacientes pediátrico ${ }^{12-14}$, aspecto que se desarrolla en el Capítulo III dedicado a terapéutica.

\section{Infecciones causadas por virus}

Los agentes virales pueden ser divididos en dos categorías. Los causantes de infecciones oportunistas, capaces de provocar una enfermedad grave en el paciente inmunocomprometido, como los virus de la familia Herpesviridae, especialmente citomegalovirus (CMV) y el virus de Epstein Barr (VEB); los virus polioma, BK y JC, de gran importancia en el manejo de pacientes receptores de $\mathrm{TPH}^{16,17}$. El segundo grupo corresponde a los virus que producen infecciones autolimitadas como los virus respiratorios que, en estos pacientes, especialmente los receptores de TPH, puede ocasionar infecciones graves por su inmunosupresión celular ${ }^{15}$. Los métodos diagnósticos para las infecciones virales han tenido un progreso notable, fundamentalmente asociado a la mejoría y estandarización de los ensayos moleculares, que aportan en sensibilidad y cuantificación de carga viral. Los ensayos clásicos como las técnicas de detección de antígenos (por técnicas de inmunofluorescencia/ELISA) están aún vigentes y los cultivos celulares se han reservado para la recuperación de cepas de interés, detección de nuevos agentes, cambios en la genética viral o ensayos de secuenciación para determinar susceptibilidad a antivirales ${ }^{18-21}$.

\section{Infecciones causadas por parásitos}

Numerosos parásitos son capaces de provocar graves enfermedades en pacientes con cáncer y TPH, especialmente aquellos en condición de inmunosupresión profunda de células $\mathrm{T}$.

La mayoría de estas infecciones se deben a parásitos intracelulares y pueden ser producidas por reactivación de una infección latente, infección primaria o reinfección.

En Chile, estos agentes se clasifican como de alta o baja relevancia, teniendo en cuenta su gravedad o su frecuencia. Es así como son de alta relevancia Toxoplasma gondii, Cryptosporidium sp, Microsporidium sp, Blastocystis sp, Giardia sp y Echinococcus sp; en cambio son de relevancia menor Cystoisospora sp, Cyclospora sp, Entamoeba histolytica, Trypanosoma cruzi, Strongyloides stercoralis, Leishmania sp, Plasmodium sp, Babesia sp, Acanthaomoeba sp y Schistosoma $\mathrm{sp}^{22}$.

El diagnóstico precoz de infección contribuye ciertamente a mejorar el pronóstico de estos pacientes. Entre las técnicas diagnósticas, la microscopia directa, las técnicas serológicas y moleculares, más un acabado estudio histológico, son las herramientas disponibles a usar en aras de optimizar un diagnóstico parasitológico ${ }^{23}$.

En las Tablas 1 a 7 se resumen los métodos diagnósticos disponibles según el órgano comprometido y los eventuales microorganismos involucrados, especificando el tipo de muestra, la técnica diagnóstica, condiciones de transporte y el nivel de requerimiento para realizar en laboratorio local o conveniencia de definir laboratorio de referencia.

\section{Exámenes de cribado de infecciones, previo al inicio de quimioterapia del cáncer 0 trasplante.}

Ante la inmunosupresión asociada al cáncer, sus tratamientos y la profunda vulnerabilidad a las infecciones durante un TPH, es importante estar en conocimiento de cuáles infecciones bacterianas, virales o parasitarias han afectado previamente al niño por el riesgo de reactivación de ellas durante este período. Asimismo, el estudio del donante de los precursores hematopoyéticos, con excepción de la sangre de cordón umbilical, informará qué inmunidad específica aportará a su hospedero.

La pesquisa se realiza por más de una técnica de laboratorio, a través de la detección de anticuerpos específicos IgG, IgM o totales, antígenos, o búsqueda de genoma de algunos agentes desde sangre, tejido o biopsia, por ejemplo. 
En la Tabla 8 se listan los principales exámenes y agentes que pueden causar complicaciones durante la inmuno supresión del paciente oncológico o receptor de trasplante.

\section{Métodos para el diagnóstico de los agentes infecciosos en material anatomopatológico}

El aporte del laboratorio de anatomía patológica en el estudio de las enfermedades infecciosas en los pacientes inmunocomprometidos representa una valiosa contribución al momento de su enfrentamiento diagnóstico, terapéutico y pronóstico. El laboratorio posee una variedad de técnicas rutinarias que pueden ser utilizadas en la mayoría de las instituciones que cuenten con un laboratorio de anatomía patológica.

Los métodos de examen o estudio anatomopatológico de las infecciones combinan, actualmente, las tradicionales e insustituibles técnicas morfológicas con métodos complementarios de tipo inmunohistoquímico y con técnicas de biología molecular ${ }^{28,29}$.

El uso de la inmunohistoquímica y la patología molecular suele reservarse para instituciones de mayor complejidad y los costos asociados a su ejecución suelen ser mayores ${ }^{30,31}$.

\section{Nivel macroscópico}

En este nivel se identifica la muestra, se observa y se describe. En los casos de piezas quirúrgicas, una adecuada observación y disección permite obtener muestras representativas de las lesiones (muestreo) para estudio histopatológico. En algunos casos, el análisis macroscópico orienta el diagnóstico, como por ejemplo, en la colonización y ocupación de cavidades orgánicas pre-existentes como los aspergilomas; en las inflamaciones mucosas pseudomembranosas asociadas a hongos del género Candida; en los infartos de tipo séptico secundarios, propios de hongos angio-invasores; o en los casos de lesiones nodulares mucinosas producidas por C. neoformans.

Las muestras pequeñas obtenidas por punción, métodos endoscópicos o biopsias incisionales, deben ser procesadas en forma completa. Biopsias de órganos completos, partes de órgano o grandes biopsias excisionales deben ser muestreadas incluyendo tejido alterado, tejido aparentemente sano, tejido de la interfase lesión-sano y material no tisular (bolas micóticas, material mucoideo, pseudomembranas, etc.).

La fijación de las muestras debe ceñirse a los protocolos estándares que tienen los laboratorios de anatomía patológica, usualmente con formalina-tampón al 10\%, en volumen y tiempo en concordancia con el tipo de muestra.
Las muestras para microscopia electrónica deben fijarse en glutaraldehido.

En esta instancia, antes de proceder a la fijación de los especímenes, es siempre mandatorio, si antes no se ha hecho, disponer de muestras para los cultivos microbiológicos correspondientes y eventualmente, para otro tipo de análisis que requiera de tejido no fijado en formalina.

Nivel de requerimiento: Deben estar disponibles en todos los centros que manejan pacientes con cáncer y TPH.

\section{Nivel microscópico habitual o de microscopia óptica}

Los análisis a este nivel de observación pueden desarrollarse en forma rápida o de manera diferida, de acuerdo con la disponibilidad de técnicas y premura de cada caso. Por otra parte, se pueden aplicar técnicas o métodos de estudio simple o complejos según los protocolos de trabajo que se planifiquen.

- Análisis rápidos con técnicas simples: Los análisis rápidos, de tejidos congelados o citología, pueden usar clarificantes como el $\mathrm{KOH}$, el lactofenol o el azul de lactofenol, o tinciones rápidas mono o policromáticas como el azul de toluidina, la tinción de Gram, Papanicolaou, Giemsa o similares, o las tinciones abreviadas de hematoxilina \& eosina y de Gomori-Grocott. En este ámbito se incluye el examen con blanco de calcoflúor, un blanqueador de algodón fluorescente que se une a la celulosa y quitina de la pared fúngica, y que exhibe fluorescencia cuando se expone a luz ultravioleta, permitiendo delinear claramente elementos fúngicos; sin embargo, tiene falsos positivos con fibras vegetales, colágeno o elastina. Las técnicas simples se emplean, preferentemente, en muestra citológica o tejidos congelados que requieren de procesamientos sencillos, de fácil observación y resolución rápida.

- Análisis diferidos con técnicas de baja y mediana complejidad. La microscopia óptica diferida habitual con tinciones corrientes o de baja complejidad -hematoxilina \& eosina, el Van Gieson- permite identificar la mayoría de los elementos fúngicos tisulares presentes en las micosis humanas, ya sea superficiales o profundas. Además, es el medio a través del cual podemos definir, de manera concluyente, el tipo de respuesta tisular frente a la infección micótica, estableciendo un diagnóstico formal.

- Análisis con técnicas de mayor complejidad: Con posterioridad a los exámenes señalados surgen las orientaciones necesarias para la aplicación de técnicas de mayor complejidad, ya sea de carácter histoquímico, inmunohistoquímico o de biología molecular. En estos estudios se emplea una variedad de tinciones e impregnaciones histoquímicas cuya finalidad es resaltar los elementos micóticos en los cortes de tejido. 
Las técnicas histoquímicas de mayor utilidad y disponibilidad en el diagnóstico anatomopatológico de las micosis humanas se pueden sistematizar de acuerdo con su sitio y mecanismo de acción ${ }^{32-34}$, a saber:

- Técnicas parietales-oxidativas: Ácido periódico base de Schiff o PAS, Gridley y Gomori-Grocott. El principio común de estas tres técnicas es la oxidación de los grupos hidroxilos de los complejos polisacáridos existentes en la pared fúngica, a grupos carbonilos (aldehídos o cetonas) en presencia de ácido periódico (PAS) o ácido crómico (Gridley y Gomori-Grocott). Los aldehídos, así formados, reaccionan posteriormente con la base Schiff (leucofucsina) coloreando la pared del hongo color rojo púrpura en el PAS y rojo rosado en el Gridley (reacción de Feulgen); el PAS se contrasta con hematoxilina de Harris y el Gridley con amarillo de metanilo. En el caso de la impregnación de Gomori-Grocott, los aldehídos reducen los complejos de nitrato de plata metenamina confiriéndole a la pared fúngica un color café-negro-grisáceo, el color está dado por el depósito de plata reducida en el sitio en que se localizan los aldehídos. La intensidad de la coloración obtenida con estas técnicas depende básicamente, de la cantidad de aldehídos presentes en la pared de los hongos. Esta impregnación puede contrastarse con verde luz o con hematoxilina \& eosina.

- Técnicas para mucina-mucopolisacáridos ácidos capsulares: Estas técnicas se emplean, básicamente, en la identificación de Cryptococcus neoformans, a través del realzamiento de su cápsula rica en mucopolisacáridos ácidos, especialmente en las llamadas variedades húmedas, que son las más frecuentes. Los dos métodos más utilizados son el mucicarmín de Mayer y el azul antiguo (ancient blue).

La tinción de mucicarmín de Mayer es una técnica que data desde 1896, cuyo colorante fundamental es el carmín de origen natural. Se han desarrollado muchas modificaciones de la tinción original, pero en todas, la cápsula de C. neoformans se tiñe de rojo, los núcleos celulares de negro o azul y el fondo es amarillento.

El azul antiguo es un colorante del grupo de los ftalocianinas, moléculas que tienen un átomo central de cobre; es una sustancia de carácter básico que se liga a los grupos ácidos de los mucopolisacáridos (sulfatados y no sulfatados $\mathrm{pH}$ dependientes) originando un compuesto salino coloreado. A menor $\mathrm{pH}$, se tiñen sólo los mucopolisacáridos ácidos sulfatados. Con esta tinción, la cápsula de C. neoformans se tiñe de azul, los núcleos celulares de rojo o rosado y el citoplasma rosado pálido.

- Técnicas para sustancias pigmentarias: La presencia de pigmentos es algo común en el reino de los hongos, incluidos algunos del tipo de la melanina o similares. Desde el punto de vista del diagnóstico anatomo-patológico, tiene importancia un grupo de hongos filamentosos pigmentados correspondientes a "Phaeohiphomycetes" o también denominados hongos dermatiáceos. La coloración de las hifas se produce por la presencia de pigmentos melánicos de la pared de las mismas, característica que puede ser evidente en los cortes histológicos teñidos con técnicas corrientes. Sin embargo, en algunos casos la pigmentación no es obvia. Por otra parte, se ha descrito que $C$. neoformans, también posee en su pared pigmentos melánicos inaparentes con las tinciones usuales, pero cuya demostración tendría valor diagnóstico en los casos de variedades secas o acapsuladas de este hongo. Por tanto, la demostración histológica de este pigmento en los hongos tisulares tiene trascendencia diagnóstica. La identificación de estas sustancias melánicas en las paredes fúngicas se basa en la propiedad de afinidad argéntica que tienen estos pigmentos, es decir, la propiedad de reducir el nitrato de plata. La técnica empleada con estos fines se denomina "Fontana-Masson"; la que es una impregnación argéntica sobre las granulaciones pigmentarias dotadas de capacidad reductora. Las zonas con melanina se tiñen negro-grisáceo y los núcleos y citoplasma celular rojo-rosado, ya que se contrasta con solución de rojo nuclear.

- Técnicas diferenciales: En este grupo se incluyen todas las variedades de tinción de Gram empleadas en cortes de tejidos. El mecanismo de esta antigua y útil tinción no es bien conocido. Sin embargo, se estima que las bacterias y otros microorganismos grampositivos poseerían una pared celular rica en grupos sulfhidrilo, los que formarían enlaces disulfuro estables con el violeta de genciana o de metilo, previo al tratamiento con tintura de yodo, reteniendo el violeta después del lavado diferenciador con alcohol-acetona y tomando el colorante de contraste (safranina, fucsina o rojo neutro). Las bacterias y microorganismos gramnegativos no retienen el violeta y se tiñen con el colorante de contraste. El punto crucial de todas las formas de tinción de Gram para tejidos es la diferenciación con alcohol o acetona, de manera que cada laboratorio debe ensayar cada método hasta precisar con exactitud el tiempo de diferenciación para su técnica. Las levaduras y esporas son habitualmente Gram positivo (azul, violeta o negro) y las hifas Gram negativo (rojo) o Gram variable.

- Otras tinciones: Otras coloraciones que están integradas a la batería dispuesta para el diagnóstico de agentes infecciosos en muestras de tejidos, son el Giemsa y similares, y las tinciones ácido-alcohol resistente. La tinción de Giemsa para secciones histológicas emplea como colorante fundamental una mezcla de derivados tiacínicos catiónicos (azur A, B y azul de metileno) 
destinados a teñir los núcleos celulares y de eosina como colorante citoplasmático. Es una excelente tinción para estimar la morfología celular, especialmente de células linfohematológicas y de agentes infecciosos intracelulares y para su diagnóstico morfológico diferencial. En las micosis profundas ha sido útil en la pesquisa de histoplasmosis, tanto en frotis como en cortes histológicos.

Las tinciones ácido-alcohol resistentes se usan rutinariamente en el diagnóstico de agentes infecciosos tisulares, particularmente de micobacterias, criptosporidios, microsporidios y en algunas esporas micóticas.

- Análisis diferidos con técnicas de alta complejidad: Corresponden al uso de técnicas inmunológicas y moleculares para llegar al diagnóstico:

- Examen con microscopia de contraste de fases, utilizado para identificar hongos capsulados como C. neoformans, dada la capacidad de refracción de luz de la gruesa cápsula micótica.

- Examen con técnicas inmunológicas con anticuerpos poli o monoclonales marcados con fluorocromos o cromógenos. El examen inmunofluorescente requiere de muestras de tejido frescas no fijadas en formalina. El examen inmunohistoquímico con cromógenos (DAB) se hace sobre cortes de muestras fijadas en formalina e incluidas en parafina; para estos análisis se dispone, en forma rutinaria, de anticuerpos monoclonales primarios para Candida que son útiles en el diagnóstico de micosis por hongos levaduriformes, para Pneumocystis spp, y para Aspergillus, este último de gran utilidad en las micosis invasoras por hialohyphomycetes. Estos exámenes inmuno-histoquímicos requieren de la elección de cortes de tejido con la presencia de elementos micóticos que se quiere identificar.

- Análisis de RPC para elementos de inserción o secuenciación de ARNr 16S, en especial a partir de muestra de tejido microdisecadas con presencia de agentes infecciosos o representativas de las lesiones estudiadas. Se dispone de estudios estandarizados para Candida spp, Aspergillus spp, Pneumocystis spp.

- Examen con técnicas de hibridación in situ fluorescente (FISH) o hibridación in situ cromogénica (CISH) en paracoccidiodomicosis.

Nivel de requerimiento: Intermedio y derivación. Dado que parte de las técnicas pueden ser implementadas en los centros que atienden a estos pacientes, se sugiere enviar los "análisis diferidos de alta complejidad" a un centro de derivación o referencia con el que se mantenga una comunicación cercana y fluida.

\section{Nivel ultramicroscópico o microscopia electrónica de transmisión}

Los análisis con microscopia electrónica de transmisión de tejido fijados en glutaraldehído o recuperado de las inclusiones en parafina, aunque lentos, son de utilidad en la caracterización ultraestructural de los elementos micóticos en los propios tejidos. Los estudios basan su observación en las características de la cápsula, pared celular, septos, membrana citoplasmática, núcleo y organelos.

Nivel de requerimiento: Derivación a un centro de referencia.

En la Tabla 9 se resume en forma esquematizada un complemento de los métodos morfológicos, inmunohistoquímicos, ultraestructurales y moleculares disponibles en el diagnóstico de enfermedades infecciosas.

\section{Patrones morfológicos de las enfermedades infecciosas}

Cada una de las muestras procesadas se somete a un examen descriptivo en que el patólogo observa, el o los patrones morfológicos ${ }^{35,36}$, que son el producto de la interacción entre el agente infeccioso y el hospedero afectado. Los patrones morfológicos son, a grandes rasgos, descritos como: patrón no reactivo, alterativo, paratrófico, hiperplásico, atrófico, vascular, inflamatorio y mixtos.

- No reactivo, en infecciones con agentes poco inmunogénicos (C. neoformans, esquistosomas adulto). Es posible también encontrarlo en infecciones en fase inicial o en tratamiento y en infecciones en pacientes inmunocomprometidos.

- Alterativo, en el que se describe necrosis y destrucción $\mathrm{y}$ es propio de infecciones invasoras localizadas, generalizadas graves (virales, bacterianas, micóticas y parasitarias), virus desmielinizantes (JC) y priones.

- Paratrófico está ejemplificado por los efectos virales citopáticos (CMV, herpesvirus, VZV, VRS, papovavirus, molusco contagioso, etc.).

- Hiperplásico, se ve hiperplasias linfoides y mieloides, hiperplasia megacariocítica (ehrlichiosis y anaplasmosis) o hiperplasia pseudo-epiteliomatosa (micosis y escabiosis).

- Atrófico, localizado puede ser secundario a compresión y el generalizado a atrofia linfática relacionada al VIH.

- Vasculares, pueden ser de vasos pequeños o medianos con oclusión luminal (por ejemplo, orden Mucorales, géneros Aspergillus, Fusarium, Paecilomyces y Pseudoallescheria; Dirofilaria inmitis y género Angiostrongylus; con trombosis e infarto. $\mathrm{O}$ de vasos sanguíneos medianos y grandes con daño parietal o adventicial (bacterias y hongos con desarrollo de aneurismas micóticos). 
- Inflamatorio, puede ser descrito como pseudomembranoso, exudativo purulento, supurado, flegmonoso o abscedado. Caseificado o granulomatoso tuberculoideo, linfoplasmocitario o mixto.

En conclusión, el uso del laboratorio de Anatomía Patológica es un gran aporte al entendimiento de las enfermedades infecciosas que afectan a los pacientes con cáncer e inmunosupresión y a los que han recibido TPH. Existen niveles de complejidad creciente para obtener un diagnóstico preciso y su implementación debe ser evaluada por cada institución; sin embargo, los requerimientos básicos macroscópicos y microscópicos con las tinciones más conocidas deben estar disponibles en todos los centros hospitalarios que reciben y manejan estos pacientes.

En forma adicional, se entrega información de las técnicas y tinciones utilizadas para identificar agentes infecciosos y una descripción general de los patrones morfológicos que se describen en los informes de anatomía patológica, que facilite la conexión entre el paciente y los resultados de sus exámenes.

\section{Resumen}

El enfrentamiento del diagnóstico diferencial y etiológico de las enfermedades infecciosas de los pacientes con cáncer, incluyendo los receptores de trasplante de precursores hematopoyéticos (TPH), debe corresponder a una decisión informada, oportuna y que repercuta directamente en una conducta médica que determine una mejor sobrevida y calidad de vida de los pacientes. El objetivo de este trabajo fue aportar en el manejo de estos pacientes desarrollando una herramienta útil al médico clínico para tomar estas decisiones. Para ello se agruparon las infecciones por sistemas comprometidos diferenciando los posibles agentes etiológicos en bacterias, virus, hongos y parásitos, explicitando los exámenes diagnósticos más relevantes, mencionando la o las técnicas recomendadas, junto con el tipo de muestra óptima para su adecuado procesamiento. De manera adicional, se incorporó el ítem "nivel de requerimiento" para sugerir lo que, a juicio de los autores y la evidencia existente, debe estar presente obligatoriamente en el centro o puede ser derivable a otro laboratorio.

Tabla 1. Métodos de laboratorio para el diagnóstico de infecciones del torrente sanguíneo

Diagnóstico de infecciones bacterianas en el torrente sanguíneo ${ }^{1}$

\section{Diagnóstico sindromático}

Infección del torrente sanguíneo asociado a catéter venoso central

\section{Técnicas diagnósticas \\ Cualitativo: tiempo diferencial} Muestra

Sangre ${ }^{2}$

Adultos: $20-30 \mathrm{ml}$ por set de hemocultivos $^{3}$

(una muestra por punción venosa periférica y otra por el catéter venoso central)

Niños: volúmenes según peso corporal $^{4}$

Cuantitativo diferencial

Cultivo de la punta del catéter

Sangre

Dos jeringas de tuberculina obtenidas de punción periférica y otra del catéter venoso central

Al día de hoy se desestima su valor predictor en el diagnóstico y se recomienda no utilizarlo

\section{Toma de muestra}

Igual volumen por frasco ${ }^{2}$ No deben pasar más de 10 minutos entre la toma de ambas muestras Pesar los frascos y consignar volumen de sangre

Igual volumen $1 \mathrm{ml}$ de sangre

De inmediato

$\mathrm{T}^{\circ}$ ambiente. Rotular jeringas para asegurar interpretación de resultados

\section{Transporte}

De inmediato

$\mathrm{T}^{\circ}$ ambiente. Rotular frascos para asegurar interpretación de resultados

$\begin{array}{lll}\begin{array}{l}\text { Sangre } \\ \begin{array}{l}\text { Adultos: } 20-30 \mathrm{ml} \text { por set de } \\ \text { hemocultivos }\end{array}\end{array} & \begin{array}{l}\text { En adultos se recomienda } \\ \text { obtener dos-tres set de cultivos } \\ \text { por episodio séptico }\end{array} & \begin{array}{l}\text { De inmediato } \\ \mathrm{T}^{\circ} \text { ambiente }\end{array} \\ \begin{array}{l}\text { Niños: volúmenes } \\ \text { según peso corporal }\end{array}{ }^{4} & \begin{array}{l}\text { En niños es recomendable dos } \\ \text { set de cultivos por episodio } \\ \text { séptico }\end{array}\end{array}$

Cultivo corriente automatizado

Identificación de hemocultivos positivos a través de técnicas moleculares o espectrometría de masa (Filmarrays Y Malditoff)
Infección del torrente catéter

${ }^{1}$ Nivel de requerimiento: deben estar disponibles en cada institución que maneje estos pacientes. ${ }^{2}$ El volumen de sangre es la variable más importante en el rendimiento de cualquier hemocultivo. Una botella debe llevar un volumen máximo de $10 \mathrm{ml}$. ${ }^{3}$ Set de hemocultivos se refiere a dos botellas inoculadas con sangre obtenida desde la misma punción. En pacientes con catéter multilumen, idealmente tomar sangre de todos los lúmenes. Si no es posible, tomar muestras al lumen que más se emplea. ${ }^{4}$ Volumen de sangre recomendado para hemocultivos en niños. 


\begin{tabular}{|c|c|c|c|c|c|}
\hline \multirow{2}{*}{$\begin{array}{l}\text { Peso } \\
(\mathrm{kg})\end{array}$} & \multirow{2}{*}{$\begin{array}{l}\text { Volemia total } \\
(\mathrm{ml})\end{array}$} & \multicolumn{2}{|c|}{ Volumen de sangre recomendada para cultivo (ml) } & \multirow{2}{*}{$\begin{array}{c}\text { Volumen total para } \\
\text { cultivo }(\mathrm{ml})\end{array}$} & \multirow{2}{*}{$\begin{array}{c}\% \text { de } \\
\text { volemia }\end{array}$} \\
\hline & & Cultivo $\mathrm{N}^{\circ} 1$ & Cultivo $\mathrm{N}^{\circ} 2$ & & \\
\hline$\leq 1$ & $50-99$ & 2 (frasco amarillo) & & 2 & 4 \\
\hline $1,1-2$ & $100-200$ & 2 (frasco amarillo) & 2 (frasco amarillo) & 4 & 4 \\
\hline $2,1-12$ & $>200$ & 3-4 (frasco amarillo) & 3-4 (frasco amarillo) & $6-8$ & 3 \\
\hline$>12-40$ & $>800$ & 10 (frasco verde) & 10 (frasco verde) & 20 & 2,5 \\
\hline$>40$ & $>2.500$ & 10-20 (1-2 frascos verde) & $10-20$ (1-2 frascos verde) & 40 & $<2$ \\
\hline
\end{tabular}

Diagnóstico de infecciones fúngicas en el torrente sanguíneo ${ }^{1}$

\section{Diagnóstico sindromático}

Infección fúngica asociada a catéter venoso central
Técnicas diagnósticas

Cualitativo:

Hemocultivos
Muestra

Sangre

Adultos: $20-30 \mathrm{ml}$ por set de hemocultivos ${ }^{4}$ (una punción por vía periférica y otra por el catéter venoso central) Niños: volúmenes según peso corporal ${ }^{5}$

Sangre

Adultos: $20-30 \mathrm{ml}$ por set de hemocultivos $^{4}$

Niños: volúmenes según peso corporal ${ }^{5}$

Toma de muestra

Igual volumen ${ }^{3}$

$<10$ minutos entre la toma de ambas muestras

Idealmente pesar los frascos y consignar volumen de sangre

Igual volumen ${ }^{1,2}$

$<10$ min entre la toma de ambas muestras

Idealmente pesar los frascos y consignar volumen de sangre

Tubo tapa amarilla (gel) clob tube Volumen: 2-4 ml

Volumen: $2 \mathrm{ml}$

Dos muestras semanales

Sangre total

Dos muestras semanales

(1-3) $\beta$-D-glucano

Detección de antígeno de Cryptococcus

Látex en sangre, LCR, suero, orina y muestras respiratorias

Antifungigrama por CIM Cepa aislada o E test
Tubo rojo sin anticoagulante Volumen: 2-4 ml

Placa de Petri o agar Sabouraud

\section{Transporte}

De inmediato

$\mathrm{T}^{\circ}$ ambiente Rotular frascos para facilitar interpretación

Técnicas de sensibilidad antifúngica

A $4{ }^{\circ} \mathrm{C}: \leq 5 \mathrm{~d}$;

$>5 \mathrm{~d}:-70^{\circ} \mathrm{C}$

$2-8{ }^{\circ} \mathrm{C}:<6 \mathrm{~h}$

$>6 \mathrm{~h}:-20^{\circ} \mathrm{C}$

A $4{ }^{\circ} \mathrm{C}: \leq 5 \mathrm{~d}$

$>5 \mathrm{~d}:-70^{\circ} \mathrm{C}$

$\mathrm{T}^{\circ}$ ambiente: hasta una semana

Sensibilidad de hemocultivos para Candida es de 50-70\%. Bact/ALERT es superior en la recuperación de C. glabrata. Sensibilidad de látex Cryptococcus cercana a 90\%. ${ }^{1}$ Nivel de requerimiento: deben estar disponibles en todos los hospitales que manejen estos pacientes. ${ }^{2}$ Si se sospecha de hongos filamentosos o dimórficos, es recomendable tomar hemocultivos en frascos de lisis centrifugación. (Contactar al laboratorio de microbiología por su disponibilidad). ${ }^{3} E$ I volumen de sangre es la variable más importante en el rendimiento de cualquier hemocultivo. Una botella debe llevar un volumen máximo de $10 \mathrm{ml}$. ${ }^{4}$ Set de hemocultivos se refiere a dos botellas inoculadas con sangre obtenida desde la misma punción. En pacientes con catéter multilumen, idealmente tomar sangre de todos los lúmenes. Si no es posible, tomar muestras al lumen que más se emplea. ${ }^{5}$ Volumen de sangre recomendado para hemocultivos en niños:

\begin{tabular}{|c|c|c|c|c|c|}
\hline \multirow{2}{*}{$\begin{array}{l}\text { Peso } \\
(\mathrm{kg})\end{array}$} & \multirow{2}{*}{$\begin{array}{l}\text { Volemia total } \\
\text { (ml) }\end{array}$} & \multicolumn{2}{|c|}{ Volumen de sangre recomendada para cultivo (ml) } & \multirow{2}{*}{$\begin{array}{l}\text { Volumen total para } \\
\text { cultivo }(\mathrm{ml})\end{array}$} & \multirow[t]{2}{*}{$\%$ de volemia } \\
\hline & & Cultivo $\mathrm{N}^{\circ} 1$ & Cultivo $\mathrm{N}^{\circ} 2$ & & \\
\hline$\leq 1$ & $50-99$ & 2 (frasco amarillo) & & 2 & 4 \\
\hline $1,1-2$ & $100-200$ & 2 (frasco amarillo) & 2 (frasco amarillo) & 4 & 4 \\
\hline $2,1-12$ & $>200$ & 3-4 (frasco amarillo) & 3-4 (frasco amarillo) & $6-8$ & 3 \\
\hline$>12-40$ & $>800$ & 10 (frasco verde) & 10 (frasco verde) & 20 & 2,5 \\
\hline$>40$ & $>2.500$ & $10-20$ (1-2 frascos verde) & 10-20 (1-2 frascos verde) & 40 & $<2$ \\
\hline
\end{tabular}

\section{Diagnóstico de infecciones virales en el torrente sanguíneo ${ }^{1}$}

\section{Agente}

Citomegalovirus

\section{Citomegalovirus} genotipificación UL974

Virus de Epstein Barr

\section{Técnicas diagnósticas}

RPC cuantitativa ${ }^{2}$ automatizado y ajustada con estándares de OMS

Búsqueda del gen UL97 asociado a resistencia de CMV a ganciclovir

RPC cualitativa/cuantitativa Sangre

\section{Muestra}

Plasma o sangre total, esta última es más sensible pero menos específica ${ }^{3}$

Sangre

\section{Toma de muestra}

Tubo con anticoagulante (EDTA) (tapa lila, tamaño adulto o pediátrico)

\section{Transporte}

El plasma separado se puede transportar a $4{ }^{\circ} \mathrm{C}-8{ }^{\circ} \mathrm{C}:<3$ días

Tubo con anticoagulante (EDTA). A $4{ }^{\circ} \mathrm{C}-8{ }^{\circ} \mathrm{C}:<3$ días Tubo adulto o pediátrico

Tubo con anticoagulante (EDTA), tapa lila. Vol: 1-3 cc

A $4{ }^{\circ} \mathrm{C}-8{ }^{\circ} \mathrm{C}:<3$ días

Tubo con anticoagulante (EDTA), tapa lila. Vol: 1-3 cc

A $4{ }^{\circ} \mathrm{C}-8^{\circ} \mathrm{C}:<3$ días

Adenovirus

RPC cualitativa/cuantitativa

Sangre 


\begin{tabular}{|c|c|c|c|c|}
\hline Virus BK & RPC cualitativa/cuantitativa & Sangre & $\begin{array}{l}\text { Tubo con anticoagulante } \\
\text { (EDTA), tapa lila. Vol: } 1-3 \mathrm{cc}\end{array}$ & $\mathrm{A} 4{ }^{\circ} \mathrm{C}-8^{\circ} \mathrm{C}:<3$ días \\
\hline Parvovirus B19 & RPC cualitativa/cuantitativa & Sangre & $\begin{array}{l}\text { Tubo con anticoagulante } \\
\text { (EDTA), tapa lila. Vol: } 1-3 \mathrm{cc}\end{array}$ & $\mathrm{A} 4{ }^{\circ} \mathrm{C}-8^{\circ} \mathrm{C}:<3$ días \\
\hline \multicolumn{5}{|c|}{$\begin{array}{l}\text { 'Nivel de requerimiento: Cualquiera de estos exámenes tiene un nivel de requerimiento intermedio, es decir puede ser realizado en cada institución o puede ser enviado a } \\
\text { un centro de referencia para su procesamiento. }{ }^{2} \text { Valores de referencia: Depende del ensayo utilizado, lo importante es comparar valores con una misma técnica y observar } \\
\text { los cambios de logaritmo de la cuantificación de las cargas virales. Por ejemplo, para los ensayos de RPC cuantificada de CMV un cambio significativo es de } 0,75 \text { log. }{ }^{3} \text { La } \\
\text { decisión de la muestra depende de cada centro, lo importante es que los pacientes se controlen siempre con la misma muestra y técnica. }{ }^{2} \text { Debe solicitarse si la carga viral } \\
\text { no desciende después de dos semanas de tratamiento antiviral bien llevado. UL97 es la mutación más frecuentemente encontrada asociada a resistencia a ganciclovir. }\end{array}$} \\
\hline \multicolumn{5}{|c|}{ Diagnóstico de infecciones parasitarias en el torrente sanguíneo ${ }^{1}$} \\
\hline Sospecha de parasitemia & Técnicas diagnósticas & Muestra & Toma de muestra & Transporte \\
\hline \multirow[t]{2}{*}{ Plasmodium spp } & $\begin{array}{l}\text { Frotis directo, gota gruesa } \\
\text { IFI y ELISA plasmodium lactato } \\
\text { deshidrogenasa ( } \mathrm{pLDH} \text { ) Histidin } \\
\text { rich protein } 2 \text { (HRP2) }\end{array}$ & Sangre total & $\begin{array}{l}\text { Tubo con EDTA (tubo de Coulter, tapa } \\
\text { morada) o heparina (tapa verde) o } \\
\text { sangre capilar obtenida en el laboratorio } \\
\text { mediante punción del pulpejo del dedo }\end{array}$ & $<30 \mathrm{~min}, \mathrm{~T}^{\circ}$ ambiente \\
\hline & RPC & Sangre total & Tubo tapa lila con anticoagulante (EDTA) & A $4{ }^{\circ} \mathrm{C}:<2-3$ días \\
\hline \multirow[t]{4}{*}{ Trypanosoma cruzi } & Frotis & Sangre total & Tubo con anticoagulante $(2 \mathrm{ml})$ & A $4{ }^{\circ} \mathrm{C}:<2$ días $^{1}$ \\
\hline & Gota gruesa & Sangre total & $\begin{array}{l}\text { Tubo sin anticoagulante tomada por } \\
\text { punción venosa o digital. } 3 \text { a } 4 \text { gotas por } \\
\text { preparación. Vol: min. } 2 \mathrm{ml}\end{array}$ & A $4{ }^{\circ} \mathrm{C}:<2$ días \\
\hline & IFI, ELISA Western Blot & Suero, plasma & $\begin{array}{l}\text { Tubo con anticoagulante (EDTA) } \\
\text { Volumen: RN 2-3 ml } \\
<10 \text { años: } 5 \mathrm{ml} \text {. Adulto: } 7-10 \mathrm{ml}\end{array}$ & A $4{ }^{\circ} \mathrm{C}:<2$ días \\
\hline & RPC & Sangre total & $\begin{array}{l}\text { Tubo con anticoagulante (EDTA) } \\
\text { (tapa lila). Volumen: } 2 \mathrm{ml}\end{array}$ & $\begin{array}{l}\text { A } 4{ }^{\circ} \mathrm{C}:<2 \text { días } \\
\text { Protegido de la luz }\end{array}$ \\
\hline
\end{tabular}

Tabla 2. Métodos de laboratorio para el diagnóstico de infecciones del sistema nervioso central (SNC)

\begin{tabular}{|c|c|c|c|c|}
\hline \multicolumn{5}{|c|}{ Meningitis/meningoencefalitis bacteriana o fúngica ${ }^{1}$} \\
\hline Agente & Técnicas diagnósticas & Muestra & Toma de muestra & Transporte \\
\hline \multirow[t]{2}{*}{ Bacterias } & $\begin{array}{l}\text { Tinción de Gram } \\
\text { Cultivo corriente }\end{array}$ & LCR & $\begin{array}{l}\text { Volumen mínimo } 1 \mathrm{ml} \\
\text { Recipiente estéril hermético }\end{array}$ & De inmediato $t^{\circ}$ ambiente \\
\hline & Detección de antígenos bacterianos (látex) & LCR & $\begin{array}{l}\text { Volumen mínimo } 1 \mathrm{ml} \\
\text { Recipiente estéril }\end{array}$ & De inmediato $t^{\circ}$ ambiente \\
\hline \multirow[t]{3}{*}{ Micobacterias } & $\begin{array}{l}\text { Baciloscopia } \\
\text { Cultivo de Koch }\end{array}$ & LCR & $\begin{array}{l}\text { Volumen mínimo } 1 \mathrm{ml} \\
\text { Tubo estéril hermético }\end{array}$ & $\begin{array}{l}\text { De inmediato } t^{\circ} \text { ambiente } \\
\text { protegido de la luz }\end{array}$ \\
\hline & Cultivo acelerado de micobacterias & & $\begin{array}{l}\text { Frasco estéril o frasco especial disponible } \\
\text { en el laboratorio, previa preparación de } \\
\text { la muestra (para tejido) }\end{array}$ & \\
\hline & $\begin{array}{l}\text { RPC tiempo real Mycobacterium tuberculosis } \\
\text { con detección de resistencia a rifampicina }\end{array}$ & & LCR para técnicas moleculares & \\
\hline \multicolumn{5}{|l|}{ Hongos } \\
\hline \multirow[t]{2}{*}{ Cryptococcus neoformans } & Tinta china & LCR & $\begin{array}{l}\text { Volumen mínimo: } 1 \mathrm{ml} \\
\text { Tubo estéril hermético }\end{array}$ & $\begin{array}{l}\text { Medidas necesarias de } \\
\text { bioseguridad }\end{array}$ \\
\hline & Detección de antígenos & & & $\mathrm{T}^{\circ}$ a $4{ }^{\circ} \mathrm{C}$ \\
\hline
\end{tabular}




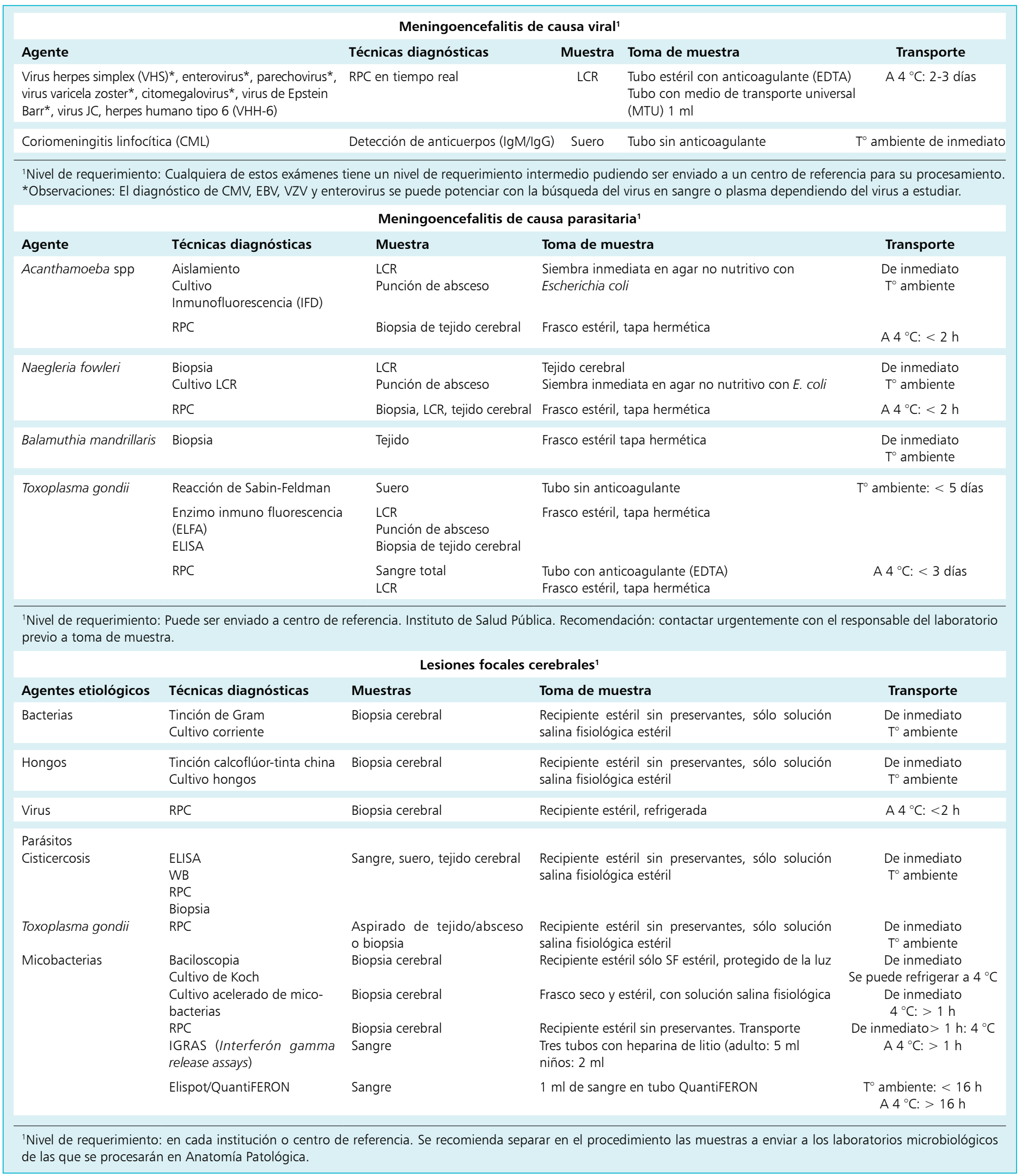


Tabla 3. Métodos de laboratorio para el diagnóstico de infecciones del tracto respiratorio

Infecciones del tracto respiratorio superior

Faringoamigdalitis ${ }^{1}$

\begin{tabular}{|c|c|c|c|c|}
\hline Agentes etiológicos & Técnicas diagnósticas & Muestras & Toma de muestra & Transporte \\
\hline \multicolumn{5}{|l|}{ Bacterias } \\
\hline \multirow[t]{2}{*}{ Bacterias } & $\begin{array}{l}\text { Tinción de Gram } \\
\text { Cultivo corriente }\end{array}$ & Secreción faríngea & $\begin{array}{l}\text { Tórula de algodón y medio de transporte } \\
\text { Stuart }\end{array}$ & $\mathrm{T}^{\circ}$ ambiente: $<1 \mathrm{~h}$ \\
\hline & Inmunocromatografía & Secreción faríngea & Tórula de rayón tubo estéril & $\mathrm{T}^{\circ}$ ambiente: $<1 \mathrm{~h}$ \\
\hline \multicolumn{5}{|l|}{ Virus } \\
\hline Adenovirus & $\begin{array}{l}\mathrm{RPC}^{2} \\
\mathrm{IFD}\end{array}$ & $\begin{array}{l}\text { Hisopado faríngeo } \\
\text { Aspirado nasofaríngeo }\end{array}$ & $\begin{array}{l}\text { Tubo de polipropileno con PBS } \\
\text { Tórula nasofaríngea en medio de transporte } \\
\text { universal para virus o PBS }\end{array}$ & De inmediato: a $4{ }^{\circ} \mathrm{C}$ \\
\hline Virus de Epstein Barr & VCA $\lg M^{3}$ & Suero & Tubo sin anticoagulante & $\mathrm{T}^{\circ}$ ambiente: $<3 \mathrm{~h}$ \\
\hline Enterovirus & $\mathrm{RPC}$ & Hisopado faríngeo o nasofaríngeo & Medio de transporte universal para virus o PBS & De inmediato a $4{ }^{\circ} \mathrm{C}$ (2-3 días) \\
\hline
\end{tabular}

${ }^{1}$ Nivel de requerimiento: debe estar disponible en cada institución o centro de referencia. ${ }^{2}$ Adenovirus: Preferir RPC por su mejor sensibilidad. ${ }^{3}$ VCA IgM VEB: Considerar en la interpretación que la ausencia de IgM positiva no descarta el diagnóstico en un paciente con inmunosupresión.

\begin{tabular}{|c|c|c|c|c|}
\hline \multicolumn{5}{|c|}{ Sinusitis $^{1}$} \\
\hline Agentes etiológicos & Técnicas diagnósticas & Muestras & Toma de muestra & Transporte \\
\hline \multirow[t]{2}{*}{ Bacterias } & Tinción de Gram & $\begin{array}{l}\text { Muestra ideal: punción de seno } \\
\text { paranasal }\end{array}$ & Secreción en tubo estéril & $\begin{array}{l}\text { De inmediato, } \\
\mathrm{T}^{\circ} \text { ambiente }\end{array}$ \\
\hline & Cultivo corriente & Secreción nasal mediante rinoscopia² & Tórula fina de rayón en la zona del meato & $\begin{array}{l}\text { De inmediato, } \\
\text { To }^{\circ} \text { ambiente }\end{array}$ \\
\hline Hongos & $\begin{array}{l}\text { Tinción de calcoflúor-KOH; } \\
\text { Cultivo }\end{array}$ & Aspirado por punción/biopsia/tejido & Contenedor aeróbico estéril. Tapa rosca & $\begin{array}{l}\text { De inmediato, } \\
\text { T}^{\circ} \text { ambiente }\end{array}$ \\
\hline \multicolumn{5}{|l|}{ Virus } \\
\hline $\begin{array}{l}\text { VRS, ADV, influenza AVB, } \\
\text { parainfluenza, rinovirus, } \\
\text { metapneumovirus, coronavirus }\end{array}$ & $\begin{array}{l}\text { RPC multiplex } \\
\text { Inmunofluorescencia (IFD) }\end{array}$ & $\begin{array}{l}\text { Aspirado sinusal hisopado nasal o } \\
\text { nasofaríngeo }\end{array}$ & Medio de transporte universal-PBS & De inmediato a $4{ }^{\circ} \mathrm{C}$ \\
\hline
\end{tabular}

${ }^{1}$ Nivel de requerimiento: debe estar disponible en cada institución o centro de referencia. ${ }^{2} E l$ estudio de secreción nasal mediante torulado simple, no es útil para diagnóstico etiológico de sinusitis. Útil sólo para estudio de portación de patógenos. La toma de muestra con rinoscopia, realizada por ORL, debe intentar obtener la muestra directamente con tórula fina de rayón desde la zona de meato donde se produce la descarga de la secreción. No tocar paredes de las fosas nasales al retirar la tórula.

Infecciones del tracto respiratorio inferior: Neumonía (patrón focal)

Bacterias y hongos ${ }^{1}$

\begin{tabular}{|c|c|c|c|c|}
\hline Agentes etiológicos & Técnicas diagnósticas & Muestras & Toma de muestra & Transporte \\
\hline \multirow[t]{5}{*}{ Bacterias } & \multirow[t]{3}{*}{ Tinción de Gram y cultivo } & Expectoración & $\begin{array}{l}\text { Recipiente estéril, boca ancha y cierre } \\
\text { hermético }\end{array}$ & $\begin{array}{l}\text { De inmediato } \\
\mathrm{T}^{\circ} \text { ambiente }\end{array}$ \\
\hline & & Aspirado endotraqueal & No diluir muestra. Recipiente estéril & \\
\hline & & Lavado bronquio-alveolar (LBA) & $\begin{array}{l}\text { Solución salina fisiológica área alveolar. } \\
\text { Recipiente estéril }\end{array}$ & \\
\hline & $\begin{array}{l}\text { Antígeno urinario de } \\
\text { Legionella sp }\end{array}$ & $\begin{array}{l}\text { Orina } 2^{\circ} \text { chorro Ideal primera orina } \\
\text { de la mañana }\end{array}$ & Frasco con tapa hermética, mínimo 2 ml & $\begin{array}{l}\text { De inmediato } \\
\mathrm{T}^{\circ} \text { ambiente }\end{array}$ \\
\hline & $\begin{array}{l}\text { Antígeno urinario de } S \text {. } \\
\text { pneumoniae }\end{array}$ & Orina $2^{\circ}$ chorro & Frasco con tapa hermética, min $2 \mathrm{ml}$ & $\begin{array}{l}\text { De inmediato } \\
\mathrm{T}^{\circ} \text { ambiente }\end{array}$ \\
\hline
\end{tabular}




\begin{tabular}{|c|c|c|c|c|}
\hline Hongos & & & & \\
\hline \multirow[t]{4}{*}{ Pneumocystis jirovecii } & IFD & Expectoración, esputo inducido o LBA & $\begin{array}{l}\text { Tubo estéril (estándar de oro por sobre } \\
\text { las tinciones) }\end{array}$ & $\begin{array}{l}\mathrm{T}^{\circ} \text { ambiente: }<2 \mathrm{~h} \\
4^{\circ} \mathrm{C}: \mathrm{si}>2 \mathrm{~h} \text { a } 7 \text { días }\end{array}$ \\
\hline & $\mathrm{RPC}$ & $\begin{array}{l}\text { Sangre } \\
\text { LBA } \\
\text { Aspirado endotraqueal nasofaríngeo } \\
\text { gárgara o expectoración inducida }\end{array}$ & $\begin{array}{l}\text { Tubo con anticoagulante (EDTA) } 3 \mathrm{ml} \\
\text { Tubo estéril con medio UTM }\end{array}$ & $4{ }^{\circ} \mathrm{C}:>2$ h a 3 días \\
\hline & Tinciones citológicas & LBA & Tubo tapa rosca estéril & $>2$ h a 14 días \\
\hline & Histología & Tejido/biopsia & Contenedor con formalina (5 ml) & $\begin{array}{l}\text { Si }>2 \text { h a } 14 \text { días } \\
\mathrm{T}^{\circ} \text { ambiente }\end{array}$ \\
\hline \multirow[t]{6}{*}{ Aspergillus spp } & $\begin{array}{l}\text { Tinción } \mathrm{KOH} \text { con calco- } \\
\text { flúor; otras tinciones para } \\
\text { hongos }\end{array}$ & Aspirado endotraqueal & Tubo estéril con tapa rosca & $\begin{array}{l}\mathrm{T}^{\circ} \text { ambiente: }<2 \mathrm{~h} \\
4^{\circ} \mathrm{C}: 2-24 \mathrm{~h}\end{array}$ \\
\hline & Cultivo hongos & LBA, muestras con cepillo protegido & Tubo estéril con tapa rosca & $\mathrm{T}^{\circ}$ ambiente: $<2 \mathrm{~h}$ \\
\hline & Histología & Tejido pulmonar & Contenedor con formalina & $\mathrm{T}^{\circ}$ ambiente: $<2 \mathrm{~h}$ \\
\hline & Galactomanano & Suero, LBA & Tubo estéril & $\begin{array}{l}4{ }^{\circ} \mathrm{C}: \leq 5 \mathrm{~d} \\
>5 \mathrm{~d}:-70{ }^{\circ} \mathrm{C}\end{array}$ \\
\hline & $\beta$-D glucano & Suero, LBA & Tubo o frasco estéril & $\begin{array}{l}\mathrm{T}^{\circ} \text { ambiente: }<2 \mathrm{~h} ; \\
4^{\circ} \mathrm{C}:>2-24 \mathrm{~h}\end{array}$ \\
\hline & $\mathrm{RPC}$ & LBA & Frasco estéril con tapa rosca & $\mathrm{T}^{\circ}$ ambiente: $<2 \mathrm{~h}$ \\
\hline \multirow[t]{3}{*}{ Cryptococcus neoformans } & $\begin{array}{l}\text { Calcoflúor-KOH u otra } \\
\text { tinción para hongos } \\
\text { Cultivo para hongos }\end{array}$ & Esputo expectorado o inducido, LBA & Tubo estéril con tapa rosca & $\begin{array}{l}\mathrm{T}^{\circ} \text { ambiente: }<2 \mathrm{~h} \\
4^{\circ} \mathrm{C}>2-24 \mathrm{~h}\end{array}$ \\
\hline & Test de antígeno & Suero, $1 \mathrm{ml}$ & Tubo estéril (3 ml) & $\begin{array}{l}\mathrm{T}^{\circ} \text { ambiente: }<1 \mathrm{~h} \\
4^{\circ} \mathrm{C}:>2-24 \mathrm{~h}\end{array}$ \\
\hline & Histología & Tejido/biopsia & Frasco con formalina & $\begin{array}{l}\mathrm{T}^{\circ} \text { ambiente: antes de } \\
2 \mathrm{~h}, 4^{\circ} \mathrm{C}:>2-24 \mathrm{~h}\end{array}$ \\
\hline \multirow[t]{4}{*}{ Fusarium spp } & $\begin{array}{l}\text { Calcoflúor-KOH u otra } \\
\text { tinción para hongos } \\
\text { Cultivo para hongos }\end{array}$ & Esputo expectorado, esputo inducido & Tubo estéril & $\begin{array}{l}\mathrm{T}^{\circ} \text { ambiente, antes de } \\
2 \mathrm{~h}, 4^{\circ} \mathrm{C}>2-24 \mathrm{~h}\end{array}$ \\
\hline & Histología & LBA & & $\mathrm{T}^{\circ}$ ambiente: $<2 \mathrm{~h}$ \\
\hline & Tinciones específicas & Tejido pulmonar & Frasco con formalina & $4^{\circ} \mathrm{C}:$ si $2-14 \mathrm{~d}$ \\
\hline & Hemocultivo para hongos & Sangre & $\begin{array}{l}\text { Frasco de hemocultivo aeróbico o } \\
\text { tubo de lisis-centrifugación }\end{array}$ & $\mathrm{T}^{\circ}$ ambiente: $<4 \mathrm{~h}$ \\
\hline $\begin{array}{l}\text { Agentes de mucormicosis: } \\
\text { Rhizopus, Mucor, } \\
\text { Absidia spp }\end{array}$ & $\begin{array}{l}\text { Calcoflúor-KOH u otra } \\
\text { tinción para hongos } \\
\text { Cultivo para hongos }\end{array}$ & $\begin{array}{l}\text { Esputo expectorado, esputo inducido } \\
\text { LBA, tejido pulmonar }\end{array}$ & Tubo estéril con tapa rosca & $\begin{array}{l}\mathrm{T}^{\circ} \text { ambiente: }<2 \mathrm{~h} \\
4^{\circ} \mathrm{C}:>2-24 \mathrm{~h}\end{array}$ \\
\hline Pseudoalescheria boydii & Cultivo para hongos & $\begin{array}{l}\text { Esputo inducido } \\
\text { LBA, tejido pulmonar }\end{array}$ & Tubo estéril con tapa rosca & $\begin{array}{l}\mathrm{T}^{\circ} \text { ambiente: }<2 \mathrm{~h} \\
4^{\circ} \mathrm{C}:>2-24 \mathrm{~h}\end{array}$ \\
\hline \multirow[t]{5}{*}{ Histoplasma capsulatum } & $\begin{array}{l}\text { Calcoflúor-KOH u otra } \\
\text { tinción para hongos }\end{array}$ & Esputo expectorado & Tubo estéril con tapa rosca & $\begin{array}{l}\mathrm{T}^{\circ} \text { ambiente: }<2 \mathrm{~h} \\
4^{\circ} \mathrm{C}:>2-24 \mathrm{~h}\end{array}$ \\
\hline & Cultivo para hongos & LBA, tejido pulmonar & Tubo estéril con tapa rosca & $\mathrm{T}^{\circ}$ ambiente: $<2 \mathrm{~h}$ \\
\hline & Hemocultivos para hongos & Sangre & $\begin{array}{l}\text { Frasco de hemocultivo aeróbico o tubo } \\
\text { de lisis-centrifugación }\end{array}$ & $\mathrm{T}^{\circ}$ ambiente: $<2 \mathrm{~h}$ \\
\hline & Test de antígeno & Suero, orina, LBA, líquido pleural & Tubo estéril con tapa rosca (2 ml) & $\mathrm{T}^{\circ}$ ambiente: $4 \mathrm{~h}$ \\
\hline & Serología & Suero & Tubo sin anticoagulante (3-5 ml) & $\begin{array}{l}\text { To ambiente: } 2 \text { días; } \\
4^{\circ} \mathrm{C}: 2-14 \text { días }\end{array}$ \\
\hline
\end{tabular}




\begin{tabular}{|c|c|c|c|c|c|c|c|c|c|}
\hline \multirow[t]{2}{*}{ Coccidioides spp } & & \multicolumn{2}{|c|}{$\begin{array}{l}\text { Calcoflúor-KOH } \\
\text { Cultivo para hongos }\end{array}$} & \multicolumn{2}{|c|}{$\begin{array}{l}\text { Esputo expectorado o inducido, } \\
\text { LBA, tejido pulmonar }\end{array}$} & \multicolumn{2}{|c|}{ Tubo estéril } & & $\mathrm{T}^{\circ}$ ambiente: $<2 \mathrm{~h}$ \\
\hline & & \multicolumn{2}{|l|}{$\lg M$ e $\lg G$} & \multicolumn{2}{|l|}{ Suero } & \multicolumn{3}{|c|}{ Tubo sin anticoagulante (3-5 ml) } & $\begin{array}{l}\mathrm{T}^{\circ} \text { ambiente: } 2 \mathrm{~d} \text {; } \\
4^{\circ} \mathrm{C}: 2-14 \mathrm{~d}\end{array}$ \\
\hline \multirow{2}{*}{\multicolumn{2}{|c|}{ Otros hongos endémicos }} & \multicolumn{2}{|c|}{$\begin{array}{l}\text { Calcoflúor-KOH u otra } \\
\text { tinción para hongos }\end{array}$} & \multicolumn{2}{|l|}{$\begin{array}{l}\text { Esputo, esputo inducido } \\
\text { LBA, tejido pulmonar }\end{array}$} & \multicolumn{3}{|c|}{ Tubo estéril tapa rosca } & $\begin{array}{l}\mathrm{T}^{\circ} \text { ambiente: }<2 \mathrm{~h} \\
4^{\circ} \mathrm{C}:>2-24 \mathrm{~h}\end{array}$ \\
\hline & & \multicolumn{2}{|l|}{$\begin{array}{l}\text { Test de antígeno } \\
\text { (Blastomyces) }\end{array}$} & \multicolumn{2}{|c|}{$\begin{array}{l}\text { Suero } \\
\text { Orina, LBA, líquido pleural }\end{array}$} & \multicolumn{3}{|c|}{$\begin{array}{l}\text { Tubo sin anticoagulante tapa rosca } \\
\text { Contenedor estéril }\end{array}$} & $\begin{array}{l}\mathrm{T}^{\circ} \text { ambiente: } 2 \mathrm{~d} \text { a } \\
4^{\circ} \mathrm{C}: 2-14 \mathrm{~d}\end{array}$ \\
\hline \multicolumn{10}{|c|}{$\begin{array}{l}\text { 'Nivel de requerimiento: en consideración a la frecuencia e importancia de un rápido diagnóstico dif } \\
\text { ensayos en cada institución y enviar a un centro de referencia aquellos que sean de incidencia menor } \\
\text { ración de la mañana, previo enjuague bucal con agua y retiro de prótesis si existe. Nebulizar y aplicar } \\
\text { calidad de la muestra: Células epiteliales }<10 / c a m p o \text { y PMN }>25 / c a m p o \text { con predominio de una mor } \\
\text { orina de la mañana por mayor concentración de antígenos bacterianos. Antígeno urinario de } S \text {. pn } \\
\text { alta tasa de colonización. Antígeno urinario de Legionella sólo detecta Legionella pneumophila serot } \\
\text { infección fúngica invasora o neutropenia febril debe sugerir el compromiso pulmonar por estos ager } \\
\text { de la microbiota normal hasta que se demuestre una enfermedad invasora. Virus: La interpretación de } \\
\text { de base del paciente, dado que, en pacientes inmunocomprometidos, la excreción viral puede ser pr }\end{array}$} \\
\hline \multicolumn{10}{|c|}{$\begin{array}{ll}\text { Neumonía (patrón focal) } \\
\text { Parásitos y micobacterias } 1\end{array}$} \\
\hline Agentes etiológicos & \multicolumn{2}{|c|}{ Técnicas diagnósticas } & \multicolumn{2}{|c|}{ Muestras } & \multicolumn{3}{|c|}{ Toma de muestra } & Transp & orte \\
\hline \multirow{2}{*}{$\begin{array}{l}\text { Parásitos } \\
\text { Echinococcus } \\
\text { granulosus }\end{array}$} & \multicolumn{2}{|c|}{$\begin{array}{l}\text { Estudio macroscópico y } \\
\text { microscópico del quiste }\end{array}$} & \multicolumn{2}{|c|}{$\begin{array}{l}\text { Vómica, material quirúrgico } \\
\text { de quiste, biopsia pulmonar }\end{array}$} & \multicolumn{3}{|c|}{ Frasco estéril tapa rosca } & \multicolumn{2}{|c|}{$\begin{array}{l}\mathrm{T}^{\circ} \text { ambiente: }<2 \mathrm{~h} \text { a } 4^{\circ} \mathrm{C}: \\
3 \mathrm{~d}\end{array}$} \\
\hline & \multicolumn{2}{|c|}{$\begin{array}{l}\text { Hemaglutinación } \\
\text { indirecta (HAI), IFI, } \\
\text { ELISA, WB, RPC }\end{array}$} & \multicolumn{2}{|c|}{ Sangre, suero } & Tubos & ticoa & Ilante & \multicolumn{2}{|c|}{$\begin{array}{l}\mathrm{T}^{\circ} \text { ambiente: }<2 \mathrm{~h} \text { a } 4^{\circ} \mathrm{C}: \\
3 \mathrm{~d}\end{array}$} \\
\hline \multirow[t]{6}{*}{ Micobacterias } & \multicolumn{2}{|c|}{ Baciloscopia } & \multicolumn{2}{|c|}{ Expectoración } & \multicolumn{3}{|c|}{ Tres muestras protegidas de la luz } & \multicolumn{2}{|c|}{$\begin{array}{l}\text { To ambiente: }<2 \mathrm{~h} \text {, puede } \\
\text { refrigerarse a } 4{ }^{\circ} \mathrm{C}\end{array}$} \\
\hline & & de Koch & $\begin{array}{l}\text { Aspirac } \\
\text { cuantit }\end{array}$ & $\begin{array}{l}\text { endotraqueal (AET) } \\
\text { tivo, LBA }\end{array}$ & $\begin{array}{l}\text { Recipie } \\
\text { estéril, }\end{array}$ & estéri & $\begin{array}{l}\text { olución salina fisiológica } \\
\text { de la luz }\end{array}$ & $\mathrm{T}^{\circ} \mathrm{ambi}$ & jiente: $<2 \mathrm{~h}$; a $4^{\circ} \mathrm{C}: 3$ \\
\hline & & $\begin{array}{l}\text { acelerado de } \\
\text { acterias }\end{array}$ & $\begin{array}{l}\text { Expectc } \\
\text { LBA }\end{array}$ & ación AET cuantitativo & $\begin{array}{l}\text { Frasco } \\
\text { fisioló }\end{array}$ & $\begin{array}{l}\text { y est } \\
\text { prote }\end{array}$ & $\begin{array}{l}\text { il, con solución salina } \\
\text { das de la luz }\end{array}$ & $\begin{array}{l}\text { De inme } \\
\text { puede } r\end{array}$ & $\begin{array}{l}\text { ediato, } \mathrm{T}^{\circ} \text { ambiente: } \\
\text { refrigerarse a } 4{ }^{\circ} \mathrm{C}\end{array}$ \\
\hline & RP & & $\begin{array}{l}\text { Expectc } \\
\text { AET cu } \\
\text { LBA }\end{array}$ & $\begin{array}{l}\text { ación } \\
\text { ntitativo }\end{array}$ & $\begin{array}{l}\text { Frasco } \\
\text { fisiolóc }\end{array}$ & y est & il, con solución salina & $\begin{array}{l}\mathrm{T}^{\circ} \mathrm{ambi} \\
>2 \mathrm{~h}\end{array}$ & $\begin{array}{l}\text { iente: }<2 \mathrm{~h} \\
4^{\circ} \mathrm{C}\end{array}$ \\
\hline & & $\begin{array}{l}\text { (Interferon gama } \\
\text { assay) }\end{array}$ & Sangre & otal & $\begin{array}{l}\text { Tres tu } \\
\text { (adultc }\end{array}$ & $\begin{array}{l}\text { de co } \\
\text { nl nir }\end{array}$ & $\begin{array}{l}\text { heparina de litio } \\
\mathrm{s}: 2 \mathrm{ml} \text { ) (Elispot) }\end{array}$ & Refriger & rar a $4{ }^{\circ} \mathrm{C}$ \\
\hline & & t/QuantiFERON) & & & $1 \mathrm{ml} \mathrm{th}$ & Quan & eron & $\mathrm{T}^{\circ} \mathrm{ambi}$ & iente, a $4{ }^{\circ} \mathrm{C}:<16 \mathrm{~h}$ \\
\hline${ }^{1}$ Nivel de requerimiento: & deb & tar disponible en ca & da insti & ión o centro de referen & & & & & \\
\hline & & & & $\begin{array}{r}\text { Neumonitis (patrón ir } \\
\text { Bacterias, micobac }\end{array}$ & $\begin{array}{l}\text { ersticia } \\
\text { rias, ho }\end{array}$ & & & & \\
\hline Agentes etiológicos & & Técnicas diagn & sticas & Muestras & & & Toma de muestra & & Transporte \\
\hline Bacterias & & $\begin{array}{l}\text { Tinción de Gram } \\
\text { Cultivo corriente }\end{array}$ & & $\begin{array}{l}\text { Expectoración } \\
\text { Calidad de la muestra } \\
<10 \times \text { campo y PMN }\end{array}$ & $\begin{array}{l}\text { élulas e } \\
25 \times c a\end{array}$ & ales & $\begin{array}{l}\text { Recipiente estéril, boca ancha } \\
\text { cierre hermético }\end{array}$ & & $\begin{array}{l}\text { De inmediato } \\
\mathrm{T}^{\circ} \text { ambiental }\end{array}$ \\
\hline & & & & Secreción traqueal & & & No diluir muestra. Recipiente & estéril & \\
\hline & & & & LBA & & & $\begin{array}{l}\text { Solución salina fisiológica } \\
\text { Recipiente estéril }\end{array}$ & & \\
\hline
\end{tabular}




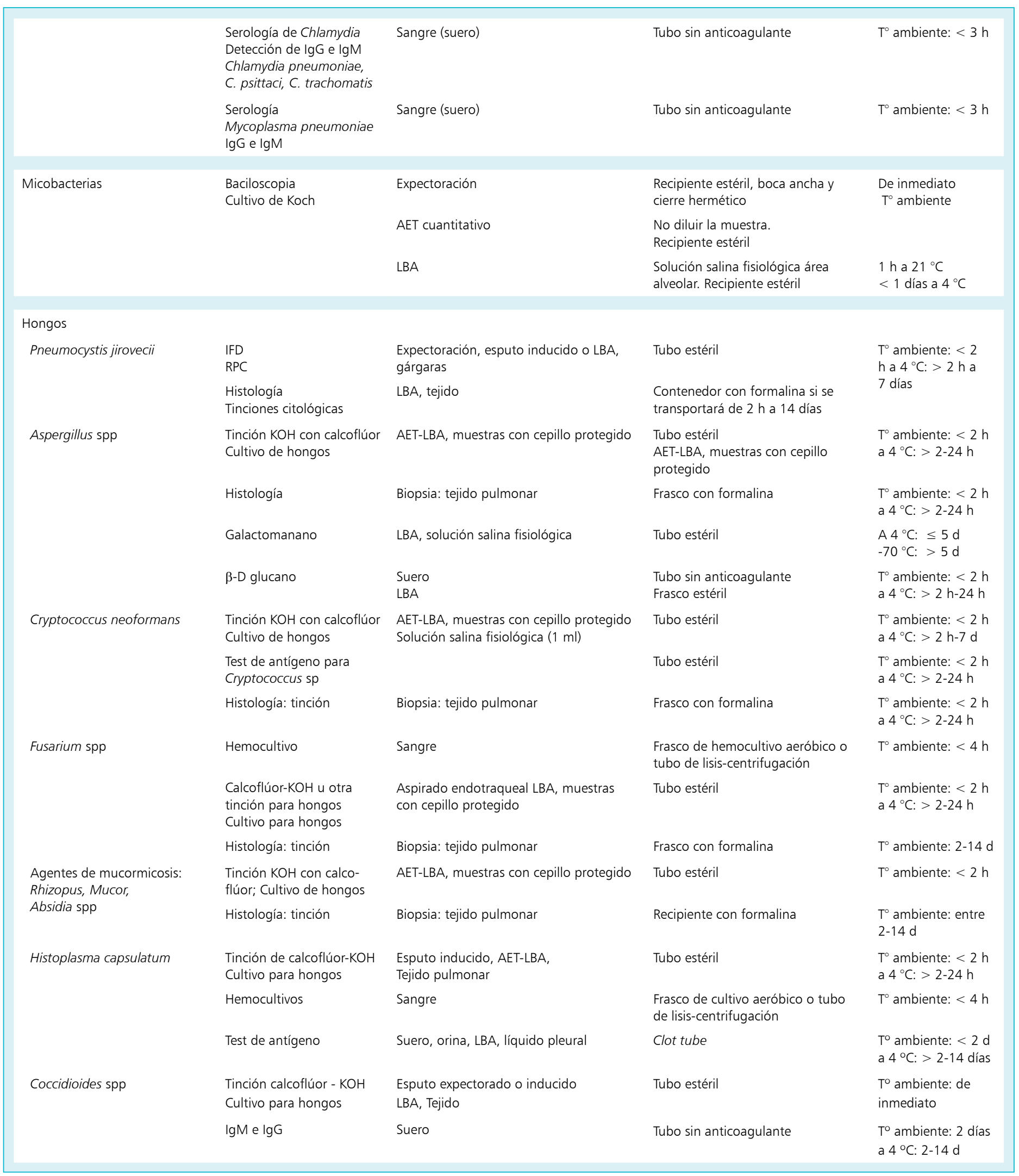




\begin{tabular}{|c|c|c|c|c|}
\hline \multirow[t]{2}{*}{ Otros hongos endémicos } & $\begin{array}{l}\text { Tinción de calcoflúor- } \mathrm{KOH} \\
\text { Cultivo hongos }\end{array}$ & $\begin{array}{l}\text { Esputo expectorado o inducido } \\
\text { Tejido pulmonar, suero, orina, LBA, } \\
\text { Líquido pleural }\end{array}$ & Tubo estéril & $\begin{array}{l}\mathrm{T}^{\circ} \text { ambiente: }<2 \mathrm{~h} \\
\text { a } 4^{\circ} \mathrm{C}:>2-24 \mathrm{~h}\end{array}$ \\
\hline & Antígeno (Blastomyces) & Sangre (suero) & Tubo sin anticoagulante & $\begin{array}{l}\text { To ambiente: } 2 \text { días } \\
\text { a } 4{ }^{\circ} \mathrm{C}: 2-14 \mathrm{~d}\end{array}$ \\
\hline
\end{tabular}

\section{Tabla 4. Métodos de laboratorio para el diagnóstico de infecciones del tracto digestivo}

\begin{tabular}{|c|c|c|c|c|}
\hline \multicolumn{5}{|c|}{ Úlceras esofágicas ${ }^{1}$} \\
\hline Agentes etiológicos & Técnicas diagnósticas & Muestras & Toma de muestra & Transporte \\
\hline Bacterias & $\begin{array}{l}\text { Tinción de Gram } \\
\text { Cultivo }\end{array}$ & Biopsia de la lesión & $\begin{array}{l}\text { Recipiente estéril, tapa hermética con } \\
\text { solución salina fisiológica estéril }\end{array}$ & $\begin{array}{l}\text { De inmediato } \\
\mathrm{T}^{\circ} \text { ambiente }\end{array}$ \\
\hline $\begin{array}{l}\text { Virus } \\
\text { Virus herpes simplex } \\
\text { Citomegalovirus }\end{array}$ & RPC-TR, cultivo viral & Biopsia de tejido & Medio de transporte universal viral & A $4{ }^{\circ} \mathrm{C}:<3$ días \\
\hline $\begin{array}{l}\text { Hongos } \\
\text { Candida spp }\end{array}$ & $\begin{array}{l}\text { Tinción de calcoflúor-KOH } \\
\text { Cultivo hongos }\end{array}$ & Tórula/biopsia de la lesión & $\begin{array}{l}\text { Recipiente estéril, tapa hermética con } \\
\text { solución salina fisiológica estéril }\end{array}$ & $\begin{array}{l}\text { De inmediato } \\
\mathrm{T}^{\circ} \text { ambiente }\end{array}$ \\
\hline & RPC & Tórula/biopsia de la lesión & $\begin{array}{l}\text { Recipiente estéril, tapa hermética con } \\
\text { solución salina fisiológica estéril }\end{array}$ & $\mathrm{A} 4-8{ }^{\circ} \mathrm{C}:<3 \mathrm{~d}$ \\
\hline & Histología & Biopsia de la lesión & Recipiente con formalina & $\mathrm{T}^{\circ}$ ambiente \\
\hline \multirow[t]{2}{*}{ Micobacterias } & Histología, inmunohistoquímica & Biopsia de la lesión & Recipiente con formalina & $\mathrm{T}^{\circ}$ ambiente \\
\hline & RPC & Biopsia de la lesión & Frasco estéril, seco & $\begin{array}{l}\mathrm{T}^{\mathrm{O}} \text { ambiente: }<2 \mathrm{~h} \\
\text { a } 4^{\circ} \mathrm{C}:>2 \mathrm{~h}\end{array}$ \\
\hline
\end{tabular}

${ }^{1}$ Nivel de requerimiento: deben estar disponibles en cada institución o con derivación rápida a un centro de referencia.

\section{Síndrome diarreico agudo'}

\begin{tabular}{|c|c|c|c|c|}
\hline Agentes etiológicos & Técnicas diagnósticas & Muestras & Toma de muestra & Transporte \\
\hline Bacterias & Coprocultivo & Deposiciones & $\begin{array}{l}\text { Recipiente limpio o tórula rectal } \\
\text { Elegir zona con pus o sangre para } \\
\text { observar al microscopio }\end{array}$ & De inmediato \\
\hline $\begin{array}{l}\text { Salmonella spp, Shigella spp, } \\
\text { Yersinia spp, Campylobacter } \\
\text { spp, Vibrio spp, Aeromonas } \\
\text { spp, Plesiomonas spp, } \\
\text { Escherichia coli diarreogénicas }\end{array}$ & $\begin{array}{l}\text { RPC (por ej.: Filmarray- } \\
\text { Biofire)* }\end{array}$ & & Recipiente estéril o en medio Cary Blair & \\
\hline Campylobacter spp & $\begin{array}{l}\text { Tinción de Hucker } \\
\text { Detección de Shiga-toxina }\end{array}$ & $\begin{array}{l}\text { Deposiciones } \\
\text { Deposiciones }\end{array}$ & $\begin{array}{l}\text { Recipiente estéril o en medio Cary Blair } \\
\text { Recipiente estéril }\end{array}$ & $\begin{array}{l}\text { De inmediato } \\
\text { De inmediato }\end{array}$ \\
\hline \multirow[t]{2}{*}{ Clostridioides difficile } & $\begin{array}{l}\text { Detección de toxina A/B y glu- } \\
\text { tamato deshidrogenasa (GDH) }\end{array}$ & Deposiciones líquidas & Recipiente estéril hermético & De inmediato \\
\hline & RPC & Deposiciones líquidas & Recipiente estéril hermético & A $4{ }^{\circ} \mathrm{C}: 2$ días \\
\hline $\begin{array}{l}\text { Rotavirus, adenovirus entérico, } \\
\text { norovirus, astrovirus }\end{array}$ & $\begin{array}{l}\text { RPC } \\
\text { Inmunocromatografía }\end{array}$ & Deposición & Frasco limpio hermético & De inmediato \\
\hline
\end{tabular}

${ }^{1}$ Nivel de requerimiento: deben estar disponibles en cada institución, pudiendo derivar a un centro de referencia los ensayos de biología molecular. *Determina los siguientes microorganismos: Bacterias: E. coli enterotoxigénica, E. coli enteropatogénica, E. coli enteroagregativa, E. coli productora de toxina tipo Shiga stx1/stx2 (incluida la identificación específica del serogrupo 0157), Shigella-E. coli enteroinvasora-Salmonella, Campylobacter (jejuni/coli/upsaliensis), Vibrio (parahaemolyticus/vulnificus/cholerae) con identificación específica de V. cholerae-Y. enterocolitica, Plesiomonas shigelloides, C. difficile (toxinas AVB), Parásitos: Cryptosporidium, Cyclospora cayetanensis, E. histolytica, G. lamblia, Virus: adenovirus F40/41, astrovirus, norovirus GI/GII, rotavirus A, sapovirus (genogrupos I, II, III y IV). 


\begin{tabular}{|c|c|c|c|c|}
\hline \multicolumn{5}{|c|}{ Estudio de parasitosis intestinal en diarrea aguda ${ }^{1}$} \\
\hline Agentes etiológicos & Técnicas diagnósticas & Muestras & Toma de muestra & Transporte \\
\hline \multirow[t]{3}{*}{ Entamoeba histolytica } & Tinción Giemsa-tricrómica & Deposición (5 g) & $\begin{array}{l}\text { Parasitológico seriado (PSD) con fijador } \\
\text { PAF, SAF o PBA }\end{array}$ & $\mathrm{T}^{\circ}$ ambiente: $<24 \mathrm{~h}$ \\
\hline & HAI, ELISA, IFI & Suero & Tubo sin anticoagulante & \\
\hline & RPC & Tejido & & \\
\hline Blastocystis hominis & $\begin{array}{l}\text { Tinción Giemsa-tricrómica, } \\
\text { hematoxilina férrica }\end{array}$ & Deposición & $\begin{array}{l}\text { Parasitológico seriado (PSD) con fijador } \\
\text { PAF, SAF o PBA }\end{array}$ & $\mathrm{T}^{\circ}$ ambiente: $<24 \mathrm{~h}$ \\
\hline \multirow[t]{2}{*}{ Giardia lamblia } & Ac monoclonales, IFI, RPC, & Deposición & $\begin{array}{l}\text { Parasitológico seriado (PSD) con fijador } \\
\text { PAF, SAF o PBA }\end{array}$ & $\mathrm{T}^{\circ}$ ambiente: $<24 \mathrm{~h}$ \\
\hline & Inmunocromatografía & Líquido duodenal & Tubo con anticoagulante $10 \mathrm{cc}$ & $\mathrm{T}^{\circ}$ ambiente: $<4 \mathrm{~h}$ \\
\hline \multirow[t]{3}{*}{ Strongyloides stercoralis } & $\begin{array}{l}\text { Método Baermann-Moraes } \\
\text { Cultivo en placa de agar } \\
\text { no nutritivo con } \\
\text { Escherichia coli }\end{array}$ & Deposición & $\begin{array}{l}\text { PSD con fijador PAF, SAF o PBA, } \\
\text { coproparasitológico }\end{array}$ & $\mathrm{T}^{\circ}$ ambiente: $<24 \mathrm{~h}$ \\
\hline & Enterotest, ELISA, WB & Líquido duodenal & Tubo con anticoagulante $10 \mathrm{cc}$ & $\mathrm{T}^{\circ}$ ambiente: $<4 \mathrm{~h}$ \\
\hline & $\mathrm{RPC}$ & Sangre & Suero en tubo con EDTA & $\mathrm{T}^{\circ}$ ambiente: $<4 \mathrm{~h}$ \\
\hline \multirow[t]{2}{*}{ Cryptosporidium spp } & $\begin{array}{l}\text { Tinción de Ziehl Neelsen, } \\
\text { Kinyoun, safranina y } \\
\text { tricrómica }\end{array}$ & Deposición & PSD método de concentración & $\mathrm{T}^{\circ}$ ambiente: $<24 \mathrm{~h}$ \\
\hline & $\begin{array}{l}\text { Técnica de Richter } \\
\text { IFD, ELISA } \\
\text { inmunocromatografía, } \\
\text { RPC cultivo }\end{array}$ & Biopsia intestinal & & \\
\hline Cyclospora spp & $\begin{array}{l}\text { Tinción de Ziehl Neelsen, } \\
\text { Kinyoun, fucsina básica y } \\
\text { safranina, fluorescencia } \\
\text { bajo luz UV }\end{array}$ & Deposición & PSD método de concentración & $\mathrm{T}^{\circ}$ ambiente: $<24 \mathrm{~h}$ \\
\hline \multirow[t]{2}{*}{ Cystoisospora spp } & $\begin{array}{l}\text { Tinción de Ziehl Neelsen } \\
\text { Kinyoun, y safranina }\end{array}$ & Deposición & $\begin{array}{l}10 \text { muestras } \\
\text { PSD método de concentración }\end{array}$ & $\mathrm{T}^{\circ}$ ambiente: $<24 \mathrm{~h}$ \\
\hline & $\begin{array}{l}\text { IFI, técnica de flotación, } \\
\mathrm{RPC}\end{array}$ & Biopsia intestino delgado & & \\
\hline \multirow[t]{2}{*}{ Microsporidia spp } & $\begin{array}{l}\text { Tinción cromotropo } 2 \mathrm{R}, \\
\text { Kinyoun }\end{array}$ & Deposición & PSD método de concentración & $\mathrm{T}^{\circ}$ ambiente: $<24 \mathrm{~h}$ \\
\hline & Calcoflúor, IFD & Biopsia & & \\
\hline \multirow[t]{3}{*}{ Schistosoma spp } & $\begin{array}{l}\text { Sedimentación espontánea } \\
\text { en deposiciones }\end{array}$ & Deposición & PSD con fijador PAF & $\mathrm{T}^{\circ}$ ambiente: $<24 \mathrm{~h}$ \\
\hline & $\begin{array}{l}\text { Coproparasitológico de } \\
\text { Kato-Katz, IFI, ELISA, WB, }\end{array}$ & Sangre & Tubo con anticoagulante (EDTA), suero & $\mathrm{T}^{\circ}$ ambiente: $<4 \mathrm{~h}$ \\
\hline & Biopsia & Biopsia de recto & Tubo hermético estéril & $\mathrm{T}^{\circ}$ ambiente: $<24 \mathrm{~h}$ \\
\hline
\end{tabular}


Tabla 5. Métodos de laboratorio para el diagnóstico de infecciones del tracto urinario

\section{Cistitis y pielonefritis}

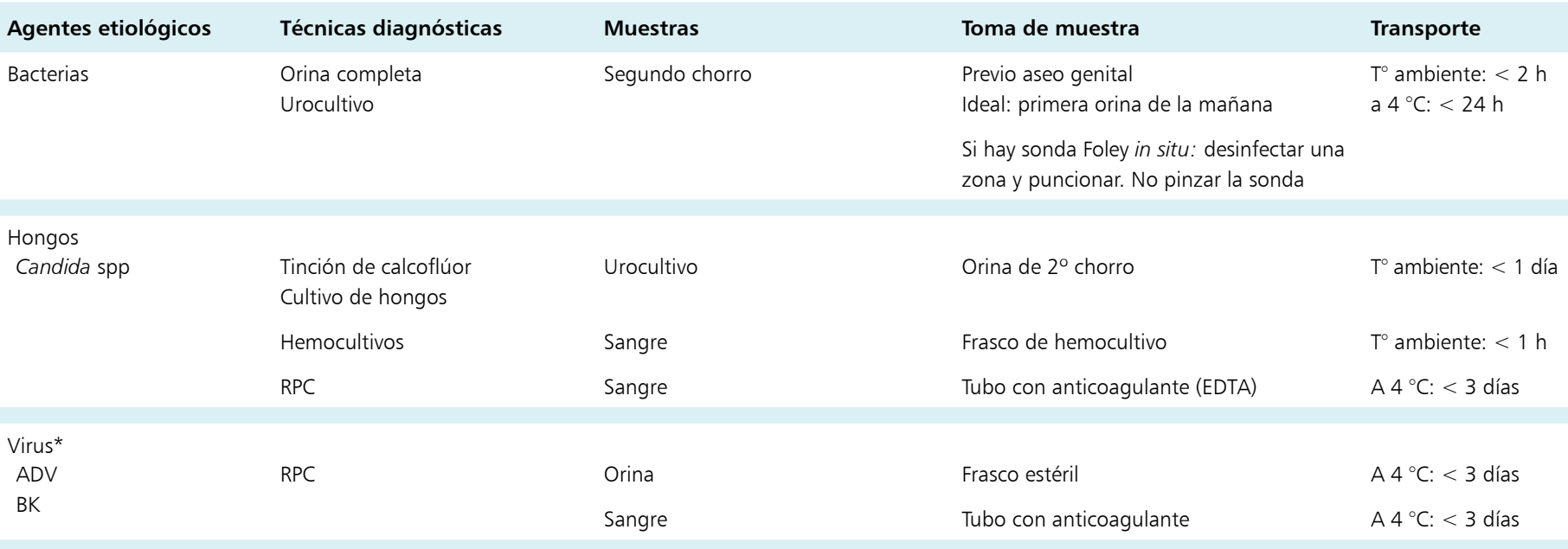

${ }^{1}$ Nivel de requerimiento: técnicas para diagnóstico de bacterias y hongos deben estar disponibles en cada institución. Técnicas de diagnóstico virológico pueden ser derivadas a centro de referencia. Comentarios: No forzar la diuresis con ingesta de líquidos pues diluye la muestra. Indicar siempre en la solicitud el método de obtención de la muestra de orina para el correcto procesamiento de esta: $2^{\circ}$ chorro, desde sonda Foley. Si la sonda Foley lleva más de 7 días, tomar la muestra habiendo cambiado previamente la sonda. La toma de cultivos desde la sonda Foley puede generar colonización de ésta en pocas horas. *La pesquisa del genoma viral en orina para ambos virus debe complementarse con un examen de RPC en sangre en pacientes con TPH.

Tabla 6. Métodos de laboratorio para el diagnóstico de infección de piel y tejidos blandos ${ }^{1}$

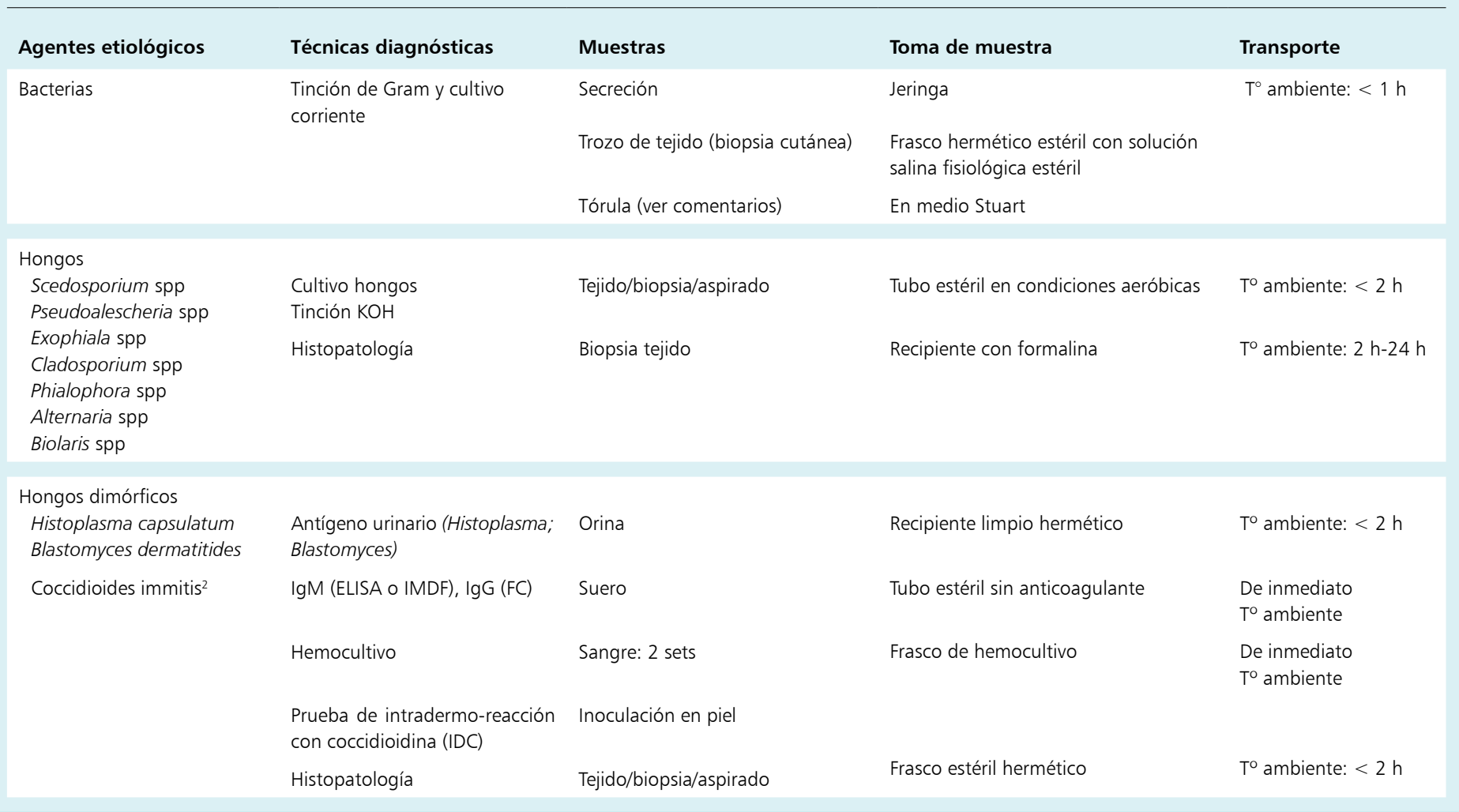




\begin{tabular}{|c|c|c|c|c|}
\hline \multirow[t]{4}{*}{ Paracoccidioides brasiliensis } & $\begin{array}{l}\text { Cultivo, tinción de hidróxido de } \\
\text { potasio, calcoflúor, IF }\end{array}$ & $\begin{array}{l}\text { Esputo, LBA, costras, úlceras, } \\
\text { nódulo linfático, LCR o biopsias } \\
\text { y tejido }\end{array}$ & Frasco estéril hermético & $T^{\circ}$ ambiente: $2 \mathrm{~h}-24 \mathrm{~h}$ \\
\hline & Hemocultivo & Sangre: dos sets & Frasco de hemocultivo & $\begin{array}{l}\text { De inmediato } \\
\text { To ambiente }\end{array}$ \\
\hline & $\lg M, \lg G(I D),(F C)$ y ELISA & Sangre & Clot tube, con anticoagulante (EDTA) & $\begin{array}{l}\text { To ambiente: } \\
\text { a } 4{ }^{\circ} \mathrm{C}:>2 \mathrm{~h}\end{array}$ \\
\hline & Histología & Tejido/biopsia/aspirado & Recipiente con formalina & $\mathrm{T}^{\circ}$ ambiente: $<24 \mathrm{~h}$ \\
\hline \multirow[t]{4}{*}{ Penicilium marneffei } & Cultivo, tinción & Tejido, biopsia, aspirado, sangre & Recipiente estéril hermético & $\begin{array}{l}\text { De inmediato } \\
\mathrm{T}^{\circ} \text { ambiente }\end{array}$ \\
\hline & Antígeno en orina (ELISA) & Orina & Frasco limpio hermético & $\begin{array}{l}\text { De inmediato } \\
\mathrm{T}^{\circ} \text { ambiente }\end{array}$ \\
\hline & $\begin{array}{l}\text { Detección de antígenos (ELISA) } \\
\text { RPC }\end{array}$ & Tejido, biopsia, aspirado & Recipiente estéril hermético & A $4{ }^{\circ} \mathrm{C}:>2$ h-3 días \\
\hline & Histología & Tejido, biopsia, aspirado & Recipiente con formalina & To ambiente: $<24 \mathrm{~h}$ \\
\hline \multirow[t]{4}{*}{$\begin{array}{l}\text { Sporotrix } \\
\text { schenckii }\end{array}$} & Cultivo & $\begin{array}{l}\text { Lesión, nódulo cutáneo, LBA, } \\
\text { tejidos, LCR }\end{array}$ & Frasco estéril hermético & $\begin{array}{l}\text { De inmediato } \\
\text { To ambiente, }^{\circ}\end{array}$ \\
\hline & IgM, IgG (aglutinación IMDF) & Suero & Clot tube, con anticoagulante (EDTA) & $\begin{array}{l}\mathrm{T}^{\circ} \text { ambiente } \mathrm{A} 4{ }^{\circ} \mathrm{C} \text { : } \\
>2 \mathrm{~h}-24 \mathrm{~h}\end{array}$ \\
\hline & $\begin{array}{l}\text { Prueba de intradermoreacción } \\
\text { con coccidioidina (IDC) }\end{array}$ & Piel & Induración de $5 \mathrm{~mm}>24 \mathrm{~h}$ & \\
\hline & Histopatología & Tejido, biopsia, aspirado & Frasco estéril hermético & To ambiente: $<2 \mathrm{~h}$ \\
\hline \multirow[t]{4}{*}{ Candida spp } & Cultivo hongos. Tinción & Tejido, biopsia, aspirado, orina & Frasco estéril hermético & $\mathrm{T}^{\circ}$ ambiente: $<2 \mathrm{~h}$ \\
\hline & $\begin{array}{l}\text { Hemocultivo } \\
\text { Ag/Ac Cándida }\end{array}$ & Sangre & Frasco hemocultivos & $\mathrm{T}^{\circ}$ ambiente: $<2 \mathrm{~h}$ \\
\hline & $\begin{array}{l}\beta \text {-D-glucano } \\
\text { RPC }\end{array}$ & Sangre & Tubo con anticoagulante (EDTA) & $\mathrm{A} 4{ }^{\circ} \mathrm{C}:<3$ días \\
\hline & Histología & Tejido/biopsia & Recipiente con formalina & To ambiente: $<24 \mathrm{~h}$ \\
\hline \multirow[t]{3}{*}{ Cryptococcus neoformans } & Tinta china, látex, Hemocultivo & Sangre; 2 sets & $\begin{array}{l}\text { Botellas de hemocultivo o con lisis } \\
\text { centrifugación }\end{array}$ & $\mathrm{T}^{\circ}$ ambiente: $<2 \mathrm{~h}$ \\
\hline & Cultivo, tinción & $\begin{array}{l}\text { Tejido, biopsia, aspirado, } \\
\text { secreción, LCR }\end{array}$ & Recipiente estéril hermético & $\begin{array}{l}\text { To ambiente } \\
\text { De inmediato }\end{array}$ \\
\hline & Histopatología & Tejido, biopsia, aspirado & Contenedor con formalina & To ambiente: $2 \mathrm{~h}-24 \mathrm{~h}$ \\
\hline $\begin{array}{l}\text { Trichosporon spp } \\
\text { Geotrichum spp } \\
\text { Malassezia spp }\end{array}$ & Histopatología & Tejido, biopsia, aspirado & Contenedor con formalina & $\mathrm{T}^{\circ}$ ambiente: $2 \mathrm{~h}-24 \mathrm{~h}$ \\
\hline \multirow[t]{3}{*}{ Fusarium spp } & Hemocultivos & Sangre; 2 sets (sólo Fusarium) & Frasco hemocultivos & $\begin{array}{l}\mathrm{T}^{\circ} \text { ambiente } \\
\text { De inmediato }\end{array}$ \\
\hline & Cultivo, tinción & $\begin{array}{l}\text { Tejido, biopsia, aspirado, } \\
\text { secreción, LCR }\end{array}$ & Recipiente estéril hermético & $\begin{array}{l}\text { To ambiente } \\
\text { De inmediato }\end{array}$ \\
\hline & Histopatología & Tejido, biopsia, aspirado & Contenedor con formalina & $\mathrm{T}^{\circ}$ ambiente: $2 \mathrm{~h}-24 \mathrm{~h}$ \\
\hline \multirow[t]{2}{*}{ Agentes de mucormicosis } & Cultivo, tinción & $\begin{array}{l}\text { Tejido, biopsia, aspirado, } \\
\text { secreción }\end{array}$ & Recipiente estéril hermético & $\begin{array}{l}T^{\circ} \text { ambiente } \\
\text { De inmediato }\end{array}$ \\
\hline & Histopatología & Tejido, biopsia, aspirado & Contenedor con formalina & To ambiente: $2 \mathrm{~h}-24 \mathrm{~h}$ \\
\hline \multicolumn{5}{|l|}{ Virus } \\
\hline VHS 1-2, VZV, enterovirus & $\begin{array}{l}\text { RPC } \\
\text { IFD }\end{array}$ & Lesión de piel, biopsia de piel & $\begin{array}{l}\text { Escoger la lesión más nueva en } \\
\text { evolución } \\
\text { Raspado de la base de la lesión } \\
\text { vesicular o úlcera }\end{array}$ & $\begin{array}{l}\text { De inmediato } \\
\text { A } 4{ }^{\circ} \mathrm{C}:<2 \mathrm{~h}\end{array}$ \\
\hline \multicolumn{5}{|c|}{$\begin{array}{l}\text { 'Nivel de requerimiento: debe estar disponible en cada institución y los ensayos de mayor complejidad derivados a un centro de referencia. Comentarios: La muestra de } \\
\text { mejor rendimiento es aquella que corresponde a un fragmento de tejido. Las muestras de menor rendimiento son los torulados, por lo que se recomienda poner la tórul } \\
\text { en medio de transporte Stuart. Las características clínicas pueden orientar en la solicitud del mejor análisis; sin embargo, en inmunosupresión los cuadros clínicos clásico } \\
\text { pueden modificarse. }{ }^{2} \text { Coccidioides spp. es un hongo potencialmente letal y de manejo riesgoso para el laboratorio. Las AC forman aerosoles infectantes muy fácilmente } \\
\text { por ello, los cultivos deben ser manejados dentro de una campana de flujo laminar con presión negativa, con nivel de bioseguridad estricto } 2 \text { con prácticas de } 3 \text {. }\end{array}$} \\
\hline
\end{tabular}


Tabla 7. Métodos de laboratorio para el diagnóstico de infecciones oculares ${ }^{1}$

\begin{tabular}{|c|c|c|c|c|}
\hline \multicolumn{5}{|c|}{ Queratitis } \\
\hline Agentes etiológicos & Técnicas diagnósticas & Muestras & Toma de muestra & Transporte \\
\hline \multirow[t]{2}{*}{ Bacterias } & $\begin{array}{l}\text { Tinción de Gram } \\
\text { Cultivo corriente }\end{array}$ & Secreción conjuntival & $\begin{array}{l}\text { Tórula fina desde ángulo externo al } \\
\text { interno del ojo; ambos ojos }\end{array}$ & $\begin{array}{l}\text { De inmediato } \\
\mathrm{T}^{\circ} \text { ambiente }\end{array}$ \\
\hline & $\begin{array}{l}\text { Cultivo: siembra directa en cuña en placas } \\
\text { de agar sangre, chocolate y MConkey }\end{array}$ & Raspado corneal & Procedimiento quirúrgico & $\begin{array}{l}\text { De inmediato } \\
\mathrm{T}^{\circ} \text { ambiente }\end{array}$ \\
\hline \multicolumn{5}{|l|}{ Virus } \\
\hline Virus herpes simplex & RPC, IFD, cultivo viral & Hisopado corneal & Tórula en medio de transporte viral & De inmediato a $4{ }^{\circ} \mathrm{C}$ \\
\hline Adenovirus & RPC & Hisopado conjuntival & Tórula en medio de transporte viral & De inmediato a $4{ }^{\circ} \mathrm{C}$ \\
\hline \multicolumn{5}{|l|}{ Parásitos } \\
\hline Acanthamoeba spp & $\begin{array}{l}\text { Calcoflúor, tinción Giemsa, } \\
\text { Inmunoperoxidasa, cultivo }\end{array}$ & Raspado o hisopado corneal & $\begin{array}{l}\text { Cultivo de lente de contacto en agar } \\
\text { no nutritivo con Escherichia coli }\end{array}$ & $\begin{array}{l}\text { De inmediato } \\
\mathrm{T}^{\circ} \text { ambiente }\end{array}$ \\
\hline \multicolumn{5}{|c|}{ Endoftalmitis } \\
\hline Agentes etiológicos & Técnicas diagnósticas & Muestras & Toma de muestra & Transporte \\
\hline Bacterias & $\begin{array}{l}\text { Tinción de Gram } \\
\text { Cultivo corriente }\end{array}$ & Líquido intraocular & $\begin{array}{l}\text { Tórula de rayón con medio de trans- } \\
\text { porte Stuart }\end{array}$ & $\begin{array}{l}\text { De inmediato } \\
\mathrm{T}^{\circ} \text { ambiente }\end{array}$ \\
\hline Hongos & $\begin{array}{l}\text { Tinción } \mathrm{KOH} \text {, calcoflúor } \\
\text { Cultivo }\end{array}$ & Líquido intraocular & Recipiente estéril hermético, tórula & $\begin{array}{l}\text { De inmediato } \\
\mathrm{T}^{\circ} \text { ambiente }\end{array}$ \\
\hline \multicolumn{5}{|l|}{ Virus } \\
\hline $\begin{array}{l}\text { Citomegalovirus } \\
\text { (Retinitis) }\end{array}$ & RPC & Humor vítreo & $\begin{array}{l}\text { Medio de transporte viral o tubo } \\
\text { estéril }\end{array}$ & $\begin{array}{l}\text { De inmediato } \\
\text { refrigerado a } 4{ }^{\circ} \mathrm{C}\end{array}$ \\
\hline
\end{tabular}

'Nivel de requerimiento: debe estar disponible en cada institución y los ensayos de mayor complejidad serán enviados a centro de referencia. Comentarios: las muestras más invasoras deben ser tomadas por oftalmólogo en pabellón, ideal aspirar con jeringa.

Tabla 8. Métodos de laboratorio para el cribado de algunas enfermedades infecciosas de importancia en trasplante precursores hematopoyéticos' ${ }^{1}(25,26)$

\begin{tabular}{|c|c|c|c|c|}
\hline Agente etiológico & Estudio del donante (vivo o cadáver) & Estudio del receptor & Muestra & Comentarios \\
\hline $\begin{array}{l}\text { Bacterias } \\
\text { Treponema pallidum }\end{array}$ & RPR (VDRL) & RPR (VDRL) & $\begin{array}{l}\text { Suero } \\
\text { Tubo sin anticoagulante }\end{array}$ & \\
\hline \multicolumn{5}{|l|}{ Virus } \\
\hline $\begin{array}{l}\text { CMV, VEB, VZV, VHS 1-2, } \\
\text { VHH6, HTLV 1, VIH }\end{array}$ & $\lg G, \lg M$ & $\lg G, M$ & $\begin{array}{l}\text { Suero } \\
\text { Tubo sin anticoagulante }\end{array}$ & $\begin{array}{l}\text { Disponible en la mayoría de los } \\
\text { centros hospitalarios e ISP }\end{array}$ \\
\hline Hepatitis B & HBsAg, anti-core HB & $\mathrm{HBsAg}$, anti-core $\mathrm{HB}$ & $\begin{array}{l}\text { Suero } \\
\text { Tubo sin anticoagulante }\end{array}$ & $\begin{array}{l}\text { Disponible en bancos de sangre } \\
\text { e ISP }\end{array}$ \\
\hline $\mathrm{VIH}$ & ELISA VIH & ELISA VIH & $\begin{array}{l}\text { Sangre } \\
\text { Tubo con anticoagulante }\end{array}$ & Usar ensayo de $4^{\text {a }}$ generación \\
\hline \multicolumn{5}{|l|}{ Parásitos } \\
\hline Toxoplasma gondii & $\begin{array}{c}\text { Reacción de Sabin-Feldman } \\
\text { Serología (ELFA) o (ELISA) } \\
\text { IFI } \\
\text { RPC }\end{array}$ & $\begin{array}{l}\text { Reacción de Sabin-Feldman } \\
\text { Serología (ELFA) o (ELISA) } \\
\text { IFI } \\
\text { RPC }\end{array}$ & $\begin{array}{l}\text { Suero } \\
\text { Sangre con anticoagulante } \\
\text { (EDTA) }\end{array}$ & $\begin{array}{l}\text { Donante cadáver: serología en } \\
\text { líquido pericárdico } \\
\text { IFI, ELISA }\end{array}$ \\
\hline
\end{tabular}

'Nivel de requerimiento: deben estar disponibles en los centros que manejen estos pacientes. 
Tabla 9. Métodos morfológicos, inmunohistoquímicos, ultraestructurales y moleculares disponibles en el diagnóstico de enfermedades infecciosas

\section{Técnicas morfológicas diferenciales}

Tinción de Gram para tejidos

Aporta en diagnóstico diferencial de Eubacterias, Actinomycetales, hongos y algunos protozoos, y tinción de Jiménez para Chlamydia sp, rickettsia y Legionella sp

Técnicas ácido-alcohol resistentes Tinciones de fucsina por ej.: ácido: Ziehl-Neelsen, Kinyoun para micobacterias, Nocardia sp, Legionella sp, esporas micóticas, criptosporidios, microsporidios, algunas estructuras parasitarias y tinción con auramina-rodamina para micobacterias

Técnicas de azur

Giemsa, May-Grunwald, Wright, etc., para visualizar protozoos intracelulares y tisulares, Pneumocystis sp, Ehrlichia sp y Anaplasma sp

Técnicas para material viral

Feulgen (ADN viral)

Floxina-tartracina de Lendrum (inclusiones virales)

Orceina de Shikata (hepatitis B)

Técnicas de hematoxilina modificada Hematoxilina férrica de Heidenhain*

Hematoxilina ácida fosfotúngstica de Mallory* *Huevos de helmintos, trofozoitos, amebas

Inmunohistoquímica Priones (proteínas infectantes)

Virus (ADN y ARN)

Bacterias

(Helicobacter pylori, micobacterias, Chlamydia sp, Bartonella sp, Treponema sp, etc.).

Hongos (Candida spp, Aspergillus spp, Pneumocystis spp, etc.).

Protozoos (Toxoplasma sp)

Técnicas ultraestructurales Infecciones virales sin y con cuerpos de inclusión

Infecciones por Mycoplasma sp, Chlamydia sp, rickettsias, Ehrlichia sp y Anaplasma sp

Infecciones bacterianas: enfermedad de Whipple y malacoplaquia

Infecciones protozoarias: microsporidiosis

\section{Referencias bibliográficas}

1.- $\quad$ Miller J M, Binnicker M J, Campbell S, Carroll $\mathrm{K} \mathrm{C}$, Chapin K C, Gilligan P H, et al. A guide to utilization of the microbiology laboratory for diagnosis of infectious diseases: 2018 Update by the Infectious Diseases Society of America and the American Society for Microbiology. Clin Infect Dis. 2018 Jun 28. DOI: 10.1093/cid/ ciy381.

2.- Patel R. MALDI-TOF MS for the diagnosis of infectious diseases. Clin Chemistry 2015; 61: 100-11. doi: 10.1373/clinchem.2014.221770

3.- Payne M, Champagne S, Lowe C, Leung V, Hinch M, Romney M G. Evaluation of the FilmArray blood culture identification panel compared to direct MALDI-TOF MS identification for rapid identification of pathogens. J Med Microbiol. 2018; 67: 1253-6. DOI: $10.1099 / \mathrm{jmm} .0 .000802$.

4.- De Pauw B, Walsh T J, Donnelly P, Stevens D A, Edwards J E, Calandra T, et al. Revised definitions of invasive fungal disease from the European Organization for Research and Treatment of Cancer/Invasive Fungal Infections
Cooperative Group and the National Institute of Allergy and Infectious Diseases Mycoses Study Group (EORTC/MSG) Consensus Group. Clin Infect Dis 2008; 46: 1813-21. DOI: $10.1086 / 588660$.

5.- Ambasta A, Carson J, Church D L. The use of biomarkers and molecular methods for the earlier diagnosis of invasive aspergillosis in immunocompromised patients. Med Mycol 2015; 53: 531-57. DOI: 10.1093/mmy/myv026.

6.- Lehrnbecher T, Robinson P D, Fisher B T, Castagnola E, Groll A H, Steinbach W J, et al. Galactomannan, Beta-D-Glucan and PCR-based assays for the diagnosis of invasive fungal disease in pediatric cancer and hematopoietic stem cell transplantation: a systematic review and meta-analysis. Clin Infect Dis. 2016; 63: 1340-8. DOI: 10.1093/cid/ ciw592.

7.- Nucci M, Nouér S A, Cappone D, Anaissie E. Early diagnosis of invasive pulmonary aspergillosis in hematologic patients: an opportunity to improve the outcome. Haematologica. 2013; 98: 1657-60. DOI: 10.3324/haematol.2013.094359.
8.- $\quad$ Aguado J M, Vázquez L, Fernández-Ruiz M, Villaescusa T, Ruiz-Camps I, Barba P, et al. Serum galactomannan versus a combination of galactomannan and polymerase chain reaction-based Aspergillus DNA detection for early therapy of invasive aspergillosis in high-risk hematological patients: a randomized controlled trial. Clin Infect Dis 2015; 60: 40514. DOI: $10.1093 / \mathrm{cid} / \mathrm{ciu} 833$.

9.- Maertens J, Maertens V, Theunissen K, Meersseman W, Meersseman P, Meers S, et al. Bronchoalveolar lavage fluid galactomannan for the diagnosis of invasive pulmonary aspergillosis in patients with hematologic diseases. Clin Infect Dis 2009; 49: 1688-93. doi: 10.1086/647935.

10.- He S, Hang J P, Zhang L, Wang F, Zhang D C, Gong F H. A systematic review and meta-analysis of diagnostic accuracy of serum 1,3-beta-d-glucan for invasive fungal infection: Focus on cutoff levels. J Microbiol Immunol Infect. 2015; 48: 351-61. DOI: 10.1016/j. jmii.2014.06.009.

11.- Zou M, Tang L, Zhao S, Zhao Z, Chen L, Chen $\mathrm{P}$, et al. Systematic review and 
meta-analysis of detecting galactomannan in bronchoalveolar lavage fluid for diagnosing invasive aspergillosis. PloS One 2012; 7 : e43347. DOI: 10.1371/journal.pone.0043347.

12.- Pascual A, Calandra T, Bolay S, Buclin T, Bille J, Marchetti O. Voriconazole therapeutic drug monitoring in patients with invasive mycoses improves efficacy and safety outcomes. Clin Infect Dis. 2008; 46: 201-11. DOI: $10.1086 / 524669$.

13.- Silva F, Navea D, Salas C, Torres J P, Catalán $\mathrm{P}$, Morales J. Análisis de concentraciones plasmáticas de voriconazol y su perfil de seguridad en pacientes oncológicos pediátricos. Rev Chilena Infectol 2016; 33 : 127-34. http://dx.doi.org/10.4067/S071610182016000200001

14.- Karthaus M, Lehrnbecher T, Lipp H-P, Kluge $\mathrm{S}$, Buchheidt D. Therapeutic drug monitoring in the treatment of invasive aspergillosis with voriconazole in cancer patients-an evidencebased approach. Ann Hematol 2015; 94: 54756oi: 10.1007/s00277-015-2333-z.

15.- Fazekas T, Eickhoff P, Rauch M, Verdianz M, Attarbaschi A, Dworzak M, et al. Prevalence and clinical course of viral upper respiratory tract infections in immunocompromised pediatric patients with malignancies or after hematopoietic stem cell transplantation. J Pediatric Hematology/Oncology 34 (6): 442-9. DOI: 10.1097/MPH.0b013e3182580bc8.

16.- Hirsch H H, Randhawa P. BK polyomavirus in solid organ transplantation. Am J Transplant. 2013; 13 Suppl 4: 179-88. DOI: 10.1111/ ajt. 12110 .

17.- Ison M G, Hayden F G. Viral infections in immunocompromised patients: what's new with respiratory viruses? Curr Opin Infect Dis 2002;15: 355-67. PMID: 12130931.

18.- Smith T F, Espy M J, Mandrekar J, Jones M F,
Cockerill F R, Patel R. Quantitative real-time polymerase chain reaction for evaluating DNAemia due to cytomegalovirus, EpsteinBarr virus, and BK virus in solid-organ transplant recipients. Clin Infect Dis 2007; 45: 1056-61. DOI: 10.1086/521909.

19.- Marchesi F, Pimpinelli F, Ensoli F, Mengarelli A. Cytomegalovirus infection in hematologic malignancy settings other than the allogeneic transplant. Hematol Oncol 2018; 36: 381-91. DOI: $10.1002 /$ hon.2453.

20.- Hayden R T, Sun Y, Tang L, Procop G W, Hillyard D R, Pinsky B A, et al. Progress in quantitative viral load testing: variability and impact of the WHO Quantitative International Standards. J Clin Microbiol 2017; 55: 423-30. DOI: 10.1128/JCM.02044-16.

21.- Lion T. Adenovirus infections in immunocompetent and immunocompromised patients. Clin Microbiol Rev. 2014;27: 441-62. DOI: 10.1128/CMR.00116-13.

22.- Hopkins H, Kambale W, Kamya M R, Staedke S G, Dorsey G, Rosenthal P J. Comparison of HRP2- and pLDH-based rapid diagnostic tests for malaria with longitudinal follow-up in Kampala, Uganda. Am J Trop Med Hyg 2007;76: 1092-7. PMID: 17556616.

23.- Johnston S P, Ballard M M, Beach M J, Causer L, Wilkins P P. Evaluation of three commercial assays for detection of Giardia and Cryptosporidium organisms in fecal specimens. J Clin Microbiol 2003; 41 (2): 623-6. PMCID: PMC149727.

24.- Wong S S, Fung K S, Chau S, Poon R W, Wong S C, Yuen K Y. Molecular diagnosis in clinical parasitology: when and why? Exp Biol Med (Maywood) 2014; 239: 1443-60. PMID: 24668556.

25.- Fishman J A, Greenwald M A, Grossi P
A. Transmission of infection with human allografts: essential considerations in donor screening. Clin Inf Dis 2012; 55: 720-7. DOI: $10.1093 / \mathrm{cid} / \mathrm{cis} 519$.

26.- Schaffner A. Pretransplant evaluation for infections in donors and recipients of solid organs. Clin Infect Dis 2001; 33 Suppl 1: S914. DOI: $10.1086 / 32089$.

27.- Derouin F, Pelloux H. Prevention of toxoplasmosis in transplant patients. Clin Microbiol Infect. 2008;14: 1089-101. DOI: 10.1111/j.1469-0691.2008.02091.x.

28.- Eyzaguirre E, Haque A K. Application of immunohistochemistry to infections. Arch Pathol Lab Med. 2008; 132: 424-31. http://www.archivesofpathology.org/doi/ pdf/10.1043/1543-2165(2008)132\%5B424:AOI TI\%5D2.0.CO\%3B2.

29.- Tenover F C. DNA hybridization techniques and their application to the diagnosis of infectious diseases. Infect Dis Clin North Am 1993; 7: 171-81. PMID: 834516.

30.- Kradin R. Diagnostic Pathology of Infectious Disease. $2^{\text {nd }}$ edition. Elsevier Philadelphia, 2017.

31.- Procop G W, Wilson M. Infectious disease pathology. Clin Infect Dis 2001; 32: 1589-601. DOI: $10.1086 / 320537$

32.- Lass-Flörl C. Zygomycosis: conventional laboratory diagnosis. Clin Microbiol Infect. 2009; 15 Suppl 5: 60-5. doi: 10.1111/j.14690691.2009.02999.x.

33.- Guarner J. Incorporating pathology in the practice of infectious disease: myths and reality. Clin Infect Dis. 2014; 59: 1133-41. doi: 10.1093/cid/ciu469.

34.- Grogan T, Reinhardt K, Jaramillo M, Lee D. An update on "special stain" histochemistry with emphasis on automation. Adv Anat Pathol 2000; 7: 110-22. PMID: 10721418. 